OAK RIDGE NATIONAL LABORATORY

nă
FED 27 Tha

\section{Influence of Coolant pH on} Corrosion of 6061 Aluminum Under Reactor Heat Transfer Conditions

S. J. Pawel

D. K. Felde

R. E. Pawel

October 1995

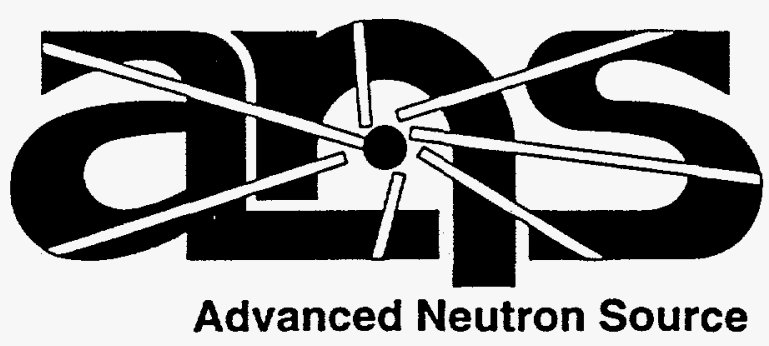

MANAGED BY

MARTIN MARIETTA ENERGY SYSTEMS, INC.

FOR THE UNITED STATES

DEPARTMENT OF ENERGY

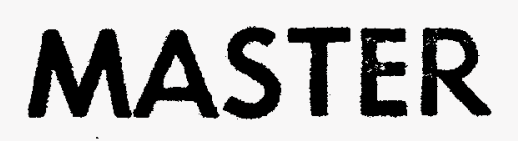


This report has been reproduced directly from the best available copy.

Available to DOE and DOE contractors from the Office of Scientific and Technical Information, P.O. Box 62, Oak Ridge, TN 37831; prices available from (615) 576-8401, FTS 626-8401.

Available to the public from the National Technical information Service, U.S. Department of Commerce, 5285 Port Royal Rd., Springtield, VA 22161.

This report was prepared as an account of work sponsored by an agency of the United States Government. Neither the United States Government nor any agency thereof, nor any of their employees, makes any warranty, express or implied, or assumes any legal liability or responsibility for the accuracy, comr pleteness, or usefulness of any information, apparatus, product, or process disclosed, or represents that its use would not iniringe privately owned rights. Reference herein to any specific commercial product, process, or service by trade name, trademark, manufacturer, or otherwise, does not necessarily constitute or imply its endorsement, recommendation, or favoring by the United States Government or any agency thereof. The views and opinions of authors expressed herein do not necessarily state or reflect those of the United States Government or any agency thereof. 


\title{
INFLUENCE OF COOLANT PH ON CORROSION OF 6061 ALUMINUM UNDER REACTOR HEAT TRANSFER CONDITIONS
}

\author{
S. J. Pawel \\ D. K. Felde \\ R. E. Pawel
}

October 1995

Prepared by

OAK RIDGE NATIONAL LABORATORY

Oak Ridge, Tennessee 37831

managed by

LOCKHEED MARTIN ENERGY SYSTEMS, INC.

for the

U.S. DEPARTMENT OF ENERGY

under contract DE-AC05-84OR21400 


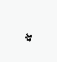

- 


\section{CONTENTS}

LIST OF FIGURES $\ldots \ldots \ldots \ldots \ldots \ldots \ldots \ldots \ldots \ldots \ldots \ldots \ldots \ldots \ldots$

LIST OF TABLES $\ldots \ldots \ldots \ldots \ldots \ldots \ldots \ldots \ldots \ldots \ldots \ldots \ldots \ldots \ldots$ vii

ACRONYMS AND SYMBOLS $\ldots \ldots \ldots \ldots \ldots \ldots \ldots \ldots \ldots \ldots \ldots \ldots \ldots \ldots$

ACKNOWLEDGEMENTS $\ldots \ldots \ldots \ldots \ldots \ldots \ldots \ldots \ldots \ldots \ldots \ldots \ldots \ldots \ldots$

ABSTRACT $\ldots \ldots \ldots \ldots \ldots \ldots \ldots \ldots \ldots \ldots \ldots \ldots \ldots \ldots \ldots \ldots \ldots \ldots \ldots \ldots \ldots \ldots$

1. INTRODUCTION $\ldots \ldots \ldots \ldots \ldots \ldots \ldots \ldots \ldots \ldots \ldots \ldots \ldots \ldots \ldots \ldots \ldots$

2. EXPERIMENTAL PROCEDURES $\ldots \ldots \ldots \ldots \ldots \ldots \ldots \ldots \ldots \ldots \ldots \ldots \ldots$

3. EXPERIMENTAL RESULTS $\ldots \ldots \ldots \ldots \ldots \ldots \ldots \ldots \ldots \ldots \ldots \ldots \ldots \ldots$

4. DISCUSSION $\ldots \ldots \ldots \ldots \ldots \ldots \ldots \ldots \ldots \ldots \ldots \ldots \ldots \ldots \ldots \ldots \ldots \ldots$

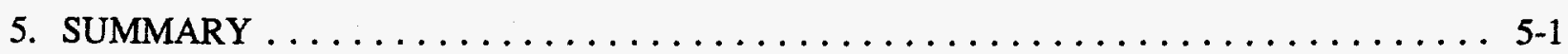

6. REFERENCES $\ldots \ldots \ldots \ldots \ldots \ldots \ldots \ldots \ldots \ldots \ldots \ldots \ldots \ldots \ldots \ldots \ldots \ldots$

Appendix A. EFFECTIVE TEST PARAMETERS FOR ANS CTESTS $\ldots \ldots \ldots \ldots \ldots$. . . 



\section{LIST OF FIGURES}

Figure

$\underline{\text { Page }}$

3.1 ANS corrosion test loop results, showing grouping of measured rate constants for film growth under the specified test conditions according

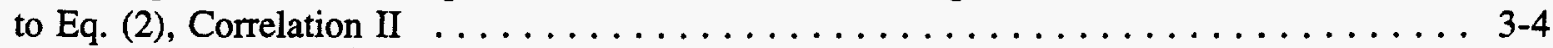

3.2 ANS corrosion test loop experimental results, showing grouping of rate constants for oxide growth on $6061 \mathrm{Al}$ compared to ANS Correlation II, suitable for coolant

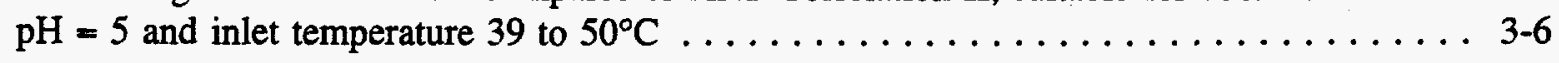

3.3 Film growth rates at the three principal specimen positions for the three stages

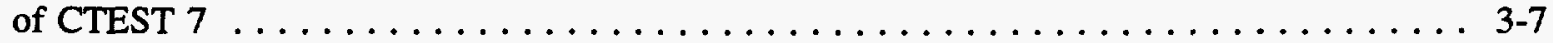

3.4 Film growth rates at the three principal specimen positions for the two stages

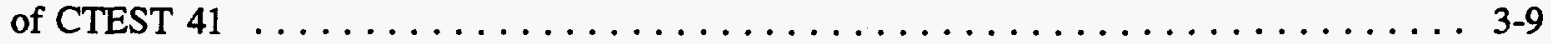

3.5 Film growth rates at the three principal specimen positions for the four stages

3.6 Film growth rates at the three principal specimen positions for the two stages of CTEST 49

3.7 Rate constant variations resulting from changes in coolant $\mathrm{pH}$ compared to the Correlation II predictions

3.8 The effect of coolant $\mathrm{pH}$ on the relative oxide growth rate constants for aluminum alloy specimens exposed in the ANS corrosion test loop with coolant inlet temperatures $\left(\mathrm{T}_{\mathrm{ci}}\right)$ less than $53^{\circ} \mathrm{C}$

3.9 The effect of coolant $\mathrm{pH}$ on the relative oxide growth rate constants for aluminum alloy specimens exposed with coolant inlet temperatures $\left(T_{c i}\right)-80^{\circ} \mathrm{C}$

4.1 Schematic drawing of the solubility of $\mathrm{Fe}$ (and $\mathrm{Cr}$ ) oxide species in aqueous solution at temperatures $T_{1}$ and $T_{2}$ as a function of the $\mathrm{pH}$ 

, 


\section{LIST OF TABLES}

Table

$\underline{\text { Page }}$

R.1 Range of experimental parameters in ANS corrosion loop tests $\ldots \ldots \ldots \ldots \ldots \ldots . \ldots$

4.1 Electron microprobe results: Fe-rich layer $\ldots \ldots \ldots \ldots \ldots \ldots \ldots \ldots \ldots \ldots$

A.1 Effective test parameters for ANS CTESTs $3-50 \ldots \ldots \ldots \ldots \ldots \ldots \ldots \ldots$ 


\section{ACRONYMS AND SYMBOLS}

ANS

HFIR

ILL

$\mathrm{k}$

L

$\mathbf{P}$

$\mathrm{pD}$

$\mathrm{pH}$

$\mathrm{pH}_{\mathrm{a}}$

$\mathbf{t}$

$T_{c}$

$T_{\mathrm{ci}}$

$T_{x / c}$

$V_{c}$

$\mathbf{x}$

$\phi$

$\phi_{\text {avg }}$
Advanced Neutron Source

High Flux Isotope Reactor

Institut Laue-Langevin

rate constant for film growth, calculated from experimental measurements;

proportional to the slope of $x^{1.351}$ vs $t$ plot as indicated in Sect. 3, Eq. (1), $\mu \mathrm{m}^{1.351} / \mathrm{h}$

electrical conductivity of coolant measured by in-line meters in bypass loop, in $\mu S / m$

electrical power dissipated in specimen, calculated from measured current and voltage drop across specimen, in $\mathrm{kW}$

analogous to $\mathrm{pH}$, for heavy water solutions

$\mathrm{pH}$ of coolant produced by nitric acid addition to demineralized water and measured by in-line meters in bypass loop at room temperature

in heavy water solution, the value measured by a common $\mathrm{pH}$ meter calibrated with light water

time of testing under specified conditions; clock started when full test thermalhydraulic conditions are attained, in $h$

local coolant temperature in flow channel, calculated from power distribution model and measurement of coolant inlet and exit temperatures, in ${ }^{\circ} \mathrm{C}$

temperature of coolant at inlet to specimen; also represents a measure of the temperature of the coolant in contact with the stainless steel components of the loop after passing through the main heat exchanger, in ${ }^{\circ} \mathrm{C}$

local interface temperature (in oxide at oxide-coolant interface), calculated from Petukhov heat transfer correlation [see Sect. 3, Eq. (2)] using local coolant temperatures, coolant velocity, local heat fluxes, and channel geometry, in ${ }^{\circ} \mathrm{C}$ coolant velocity in specimen flow channel, calculated from mass velocity via calibrated orifice meter and channel dimensions, in $\mathrm{m} / \mathrm{s}$ reaction product (boehmite) film thickness, calculated from experimental measurements during test; end-of-test measurements conducted by eddy current devices and by metallographic cross-section observations, in $\mu \mathrm{m}$ local heat flux, calculated from total specimen power, temperature measurements, and known resistivity-temperature measurements, and known resistivity-temperature function for $6061 \mathrm{Al}$ and other dilute $\mathrm{Al}$ alloys, in $\mathrm{MW} / \mathrm{m}^{2}$ average heat flux across active surface on specimen, calculated from specimen power and geometry of specimen channel, in $\mathrm{MW} / \mathrm{m}^{2}$ 



\section{ACKNOWLEDGEMENTS}

The authors are grateful for the sustained help of the many people involved with the ANS Corrosion Test Loop Program at Oak Ridge National Laboratory. In particular, M. T. McFee was the primary operator of the test loop and the associated equipment. J. F. King, D. A. Frederick, J. D. McNabb, D. W. Swaney, L. D. Chitwood, R. R. Steele, and T. S. Geer were involved at various stages with fabrication of the test sections and subsequent specimen examinations. O. B. Cavin and T. J. Henson performed the X-ray and electron probe analyses. Thanks are also extended to G. L. Yoder, R. E. Mesmer, and J. C. Griess for sharing their expertise and experience through many solicited consultations. The authors also appreciate the continuing support of D. L. Selby and C. D. West of the ANS Project staff. They, along with D. F. Wilson, reviewed the manuscript and contributed helpful suggestions. 



\begin{abstract}
To support the design of the Advanced Neutron Source (ANS), an experimental program was conducted wherein aluminum alloy specimens were exposed at high heat fluxes to high-velocity aqueous coolants in a corrosion test loop: The aluminum alloys selected for exposure were candidate fuel cladding materials, and the loop system was constructed to emulate the primary coolant system for the proposed ANS reactor. One major result of this program has been the generation of an experimental database defining oxide film growth on 6061 aluminum alloy cladding as a function of a wide range of the several variables that influence the corrosion behavior. Additionally, a data correlation was developed from the database to permit the prediction of film growth for any reasonable thermal-hydraulic excursion. This capability was utilized effectively during the conceptual design stages of the reactor.

During the course of this research, it became clear that the kinetics of film growth on the aluminum alloy specimens were sensitively dependent on the chemistry of the aqueous coolant and that relatively small deviations from the intended $\mathrm{pH} 5$ operational level resulted in unexpectedly large changes in the corrosion behavior. Examination of the kinetic influences and the details of the film morphology suggested that a mechanism involving mass transport from other parts of the test loop was involved. Such a mechanism would also be expected to be active in the operating reactor.

This report emphasizes the results of experiments that best illustrate the influence of the nonthermal-hydraulic parameters on film growth and presents data to show that comparatively small variations in $\mathrm{pH}$ near 5.0 invoke a sensitive response. Simply, for operation in the temperature and heat flux range appropriate for the ANS studies, coolant $\mathrm{pH}$ levels from 4.5 to 4.9 produced significantly less film growth than those from $\mathrm{pH} 5.1$ to 6 . A mechanism for this behavior based on the concept of treating the entire loop as an active corrosion system is presented. While the model and mechanism are speculative, most of the experimental observations are at least qualitatively consistent with it. Several ramifications of these results pertinent to reactor operation in either light or heavy water systems are discussed.
\end{abstract}




\section{INTRODUCTION}

Although aluminum is inherently highly reactive, the pure material and its alloys are generally resistant to significant oxidation because of the thin, highly protective product film formed under most exposures. Even at temperatures approaching the melting point, the product film in gaseous oxidants grows only slowly and for all practical purposes remains less than one micrometer or so in thickness. In concordance, the physical attributes of aluminum oxide, alumina, are responsible for many important commercial alloys that resist oxidation and corrosion at elevated temperatures in aggressive atmospheres.

The corrosion behavior of aluminum in aqueous media, however, is known to be more complex, and reaction rates can vary from nil to rapid, depending upon the thermal, chemical, and physical environment. Partly because of their low cost and ease of fabrication, as well as their favorable corrosion properties in certain media, aluminum alloys are the materials of choice for a myriad of commercial and industrial items.

In this context, aluminum alloys were the subject of considerable interest and research during the development stages of many nuclear research reactors. For example, beginning in the early 1950 s, a number of these alloys were used extensively as fuel cladding for water-cooled assemblies. Most reactors utilized cooling circuits of high-purity water (either $\mathrm{H}_{2} \mathrm{O}$ or $\mathrm{D}_{2} \mathrm{O}$ ) at comparatively low temperature, and it was envisioned that aluminum alloys would provide superior properties for use in this environment. High thermal conductivity and good fabricability were key features, particularly for fuel cladding. However, as their use expanded, operational problems arose that were associated with aqueous corrosion and, in particular, with the formation and distribution of the corrosion products on surfaces and in the primary coolant system. During this time, a number of experimental studies dealing with aluminum corrosion behavior supported reactor operations; the most visible efforts were mainly at Oak Ridge National Laboratory [High Flux Isotope Reactor (HFIR)], ${ }^{1-3}$ Idaho National Engineering Laboratory (Advanced Test Reactor and others), ${ }^{2,4-9}$ and Savannah River Laboratory (Savannah River Production Reactor). ${ }^{10,11}$ In addition, numerous fundamental studies of aluminum corrosion behavior were in progress at other laboratories across the country.

A major finding of this investigation was the fact that the aqueous corrosion of aluminum was influenced by the presence of a high heat flux. Corrosion product films formed under typical reactor conditions were often relatively thick and, because of their low thermal conductivity, could potentially lead to excessive temperatures in the fuel and cladding. The early experiments studied the behavior of film growth under heat transfer conditions for a range of coolant properties and temperatures at heat fluxes up to $-6 \mathrm{MW} / \mathrm{m}^{2}$. A basic understanding of the prominent features of the corrosion process evolved, eventually including the means to predict the extent of reaction product film growth for a limited range of aluminum temperatures and coolant parameters. The Griess Correlation ${ }^{1,2}$ and the Kritz Correlation ${ }^{10,11}$ are two of several documented data correlations that have been used extensively (sometimes outside the range of their intended applicability) to predict oxide layer growth on aluminum cladding under reactor conditions. Comparisons of these correlations with the recent correlation proposed for the wide-range data set investigated for the Advanced Neutron Source (ANS) have been made previously. ${ }^{12}$

The high heat flux and high coolant velocity anticipated for the ANS core were well outside the ranges considered by any previous correlation. Thus, the ANS corrosion test loop task was created to provide additional information, a more extensive database and, ideally, a modified or new film growth correlation. The last objective was to provide specifically a means for predicting the time-dependent oxide thickness during an ANS fuel cycle. This knowledge was important to reactor designers to define operating limits and to assign safety envelopes and margins. Because of its long history of satisfactory performance as a fuel cladding in experimental reactors, $6061 \mathrm{Al}$ (nominal composition: 
$0.6 \mathrm{wt} \% \mathrm{Si} ; 1.0 \mathrm{wt} \% \mathrm{Mg}$; trace $\mathrm{Fe}, \mathrm{Cr}, \mathrm{Mn}$ ) was the primary alloy of choice for the ANS, and the present main series of experiments focused on this alloy.

While the ANS experimental results concerning the influence of coolant chemistry on the corrosion process for $6061 \mathrm{Al}$ were not completely unforeseen, the sensitivity to small $\mathrm{pH}$ variations was surprising. Operating and research experience at the Savannah River Laboratory and Idaho National Engineering Laboratory in particular had suggested that coolant water chemistry played an important part in determining the nature of aluminum alloy cladding corrosion and in coolant turbidity. Tight control of primary coolant $\mathrm{pH}$ and coolant purity through effective bypass demineralization was found to be essential. Corrosion research on several aluminum alloys in test loops at Oak Ridge National Laboratory by Griess and associates ${ }^{1.2}$ found that important differences in the measured film growth rates occurred when the coolant acidity was decreased from $\mathrm{pH} 5.0$ to above $\mathrm{pH}$ 5.7. These results were decisive in the assignment of $\mathrm{pH} 5$ for primary coolant operation in HFIR and as a basic guideline for other Al-clad research reactors.

Thus, most of the present experimental efforts using the ANS corrosion test loop were conducted at $\mathrm{pH}$ 5. During the course of testing, however, it became clear that much of the scatter in the observed film growth rate data could be attributed to experimental problems in the bypass loop resulting in inadvertent, relatively minor variations in the coolant $\mathrm{pH}$. Eventually, to establish this point further, several tests were conducted that illustrated in a direct manner the sensitivity and the extent of the coolant chemistry's effect on film growth behavior. This report will present these data and illustrate their significance in the context of the complete ANS corrosion database. 


\section{EXPERIMENTAL PROCEDURES}

The ANS corrosion test loop facility has been described in detail in earlier publications, ${ }^{12-16}$ and only a summary will be included here. The specimens consisted essentially of odd-cross-section rectangular tubes of the aluminum alloy under consideration, having a flow channel with a gap width of $1.27 \mathrm{~mm}$ (corresponding to the design width of the ANS coolant channels). Each specimen was instrumented on its outer side along the $165-\mathrm{mm}$ active length with ten type $\mathrm{N}$ sheathed thermocouples (seven on one side, three on the other), surrounded by preformed electrical and thermal insulation and supplied with pressure backing plates. The specimen was welded to large aluminum electrodes providing coupling to the electrical and coolant systems that composed the test loop. The test loop was fashioned after the primary coolant system in several existing research reactors. The heat exchanger, pumps, piping, and allied equipment were purposefully constructed entirely of 304L stainless steel. A bypass system facilitated measurements of the coolant water properties, as well as permitting coolant water purification and chemistry $(\mathrm{pH})$ adjustments as necessary. Resistive heating accompanying the large currents in the specimen produced the heat flux that was transferred to the coolant in the flow channel. As low-conductivity oxidation products formed and grew at the reaction surfaces of the specimen in contact with the coolant, the measured temperatures on the outer surface of the specimen increased proportionately.

In conjunction with power and coolant flow measurements, the specimen temperatures recorded during the experiment served as input to computer codes that modeled heat generation and heat flow in the specimen and calculated the oxide film thicknesses along its length as a function of time along with other important system descriptors. An evaluation of the accuracy of these calculations was obtained at the conclusion of the experiment when direct physical measurements of these film thicknesses were made. Generally, the values were in excellent agreement with each other. Experimental attention was directed to three principal positions along the specimen: $25.4 \mathrm{~mm}$ from the coolant inlet end (position 2), at the specimen axial center (position 4), and, symmetrically, $25.4 \mathrm{~mm}$ from the coolant exit (position 6). Measurements from these three positions offer segments with a range of thermal parameters for study in a single steady-state test.

A loop experiment was typically conducted under conditions of constant power to the specimen, constant coolant inlet temperature, constant coolant flow rate, and constant coolant $\mathrm{pH}$ (the latter controlled by water purification via mixed-bed demineralization followed by dilute nitric acid additions in the bypass loop). Control of the power and coolant flow during most tests was considered excellent. Sometimes $\mathrm{pH}$ control was erratic, but $\mathrm{pH}$ rarely varied by more than a few tenths of a unit. Most recent experiments were conducted with $\mathrm{pH}$ variations within $\pm 0.1 \mathrm{pH}$ unit, and only occasionally did chemistry excursions exceed this range.

In addition to the calculation of the local temperatures, heat fluxes, and film thicknesses along the specimen during the experiment, a posttest examination of each specimen was made employing conventional analytical techniques. The thickness of the product films along each main side of the rectangular flow channel was first measured with eddy current devices. Segments of the specimen corresponding to the principal thermocouple positions were then excised in order to examine film morphology and to make direct metallographic cross-section thickness measurements for comparison with the calculated (and eddy current) values. The final film thicknesses reported in the master table in Appendix A were determined from the metallographic cross sections, regarded as the most reliable of the available measurements. X-ray analyses and electron microprobe traces were also obtained on many of the specimens to identify the reaction products and to characterize the distribution of minor elements in the alloy and the product films. Otherwise unpublished details of the individual test procedures and results can be found in the ANS monthly reports. ${ }^{17}$ 



\section{EXPERIMENTAL RESULTS}

The major results of the ANS corrosion loop test program have been reported in ANS progress reports, ${ }^{18}$ ORNL reports, ${ }^{19-24}$ and open-literature publications, ${ }^{12-15,25,26}$ and will not be recounted in detail here except for those that deal specifically with the influence of coolant $\mathrm{pH}$ upon the film growth rate. Basically, the characteristics of film growth on $6061 \mathrm{Al}$ were examined for the range of conditions pertinent to the proposed ANS operation. Several tests were conducted with other aluminum alloys including pure $\mathrm{Al}, 1100 \mathrm{Al}, 8001 \mathrm{Al}$, and a special alloy used as cladding in the Institut LaueLangevin (ILL) facility, the high-flux reactor at Grenoble, France. While different behavior associated with spallation and internal reactions was observed for these alloys, the film growth kinetics process prior to spallation was essentially identical to that for $6061 \mathrm{Al}$. The key system parameters and the complete bounds and maximum interest range for all experiments are given in Table 3.1. In addition, a table containing specific information for each test in the ANS database is included in Appendix A.

Corrosion product growth was characterized in these tests, and the important features of the process may be summarized as follows:

a. A corrosion product film consisting mainly of boehmite $\left(\mathrm{Al}_{2} \mathrm{O}_{3} \cdot \mathrm{H}_{2} \mathrm{O}\right)$ grew at a decreasing rate throughout steady-state loop experiments under ANS thermal-hydraulic conditions. The films were reasonably uniform in thickness, particularly for layers greater than $-5 \mu \mathrm{m}$. The good agreement between the measured end-of-test and the calculated film thickness values confirmed the accuracy of the published value for the thermal conductivity of boehmite, $2.25 \mathrm{~W} /(\mathrm{m} \cdot \mathrm{K}){ }^{2}$

b. At "low" coolant $\mathrm{pH}$ values (4.5-5.0) and "low" coolant inlet temperatures $\left(<57^{\circ} \mathrm{C}\right)$, a thin Fe-rich layer was generally found on the outer surface of the boehmite. On the other hand, several experiments conducted at pH 6 (nominal) yielded comparatively high film growth rates and little, if any, iron enrichment of the outer boehmite layer. The existence of the Fe-rich layer was consistently associated with lower film growth rates, and its action as a corrosion barrier was proposed. The effect of water chemistry $(\mathrm{pH})$ and test section inlet temperature $\mathrm{T}_{\mathrm{ci}}$ (or the

Table 3.1. Range of experimental parameters in ANS corrosion loop tests

\begin{tabular}{lll}
\hline \multicolumn{1}{c}{ Parameter } & $\begin{array}{c}\text { Experimental range } \\
\text { (nominal) }\end{array}$ & $\begin{array}{c}\text { Maximum interest } \\
\text { range }\end{array}$ \\
\hline Coolant, $\mathrm{pH}^{a}$ & $4.5-6.0$ & $5 \pm 0.2$ \\
Coolant velocity $\left(\mathrm{V}_{\mathrm{c}}\right), \mathrm{m} / \mathrm{s}$ & $9-28$ & $25-27.6$ \\
Coolant inlet temperature $\left(\mathrm{T}_{\mathrm{c}}\right),{ }^{\circ} \mathrm{C}$ & $39-80$ & $44-49$ \\
Local coolant temperature $\left(\mathrm{T}_{\mathrm{c}}\right),{ }^{\circ} \mathrm{C}$ & $45-101$ & $50-90$ \\
Local interface temperature ${ }^{b}\left(\mathrm{~T}_{\mathrm{x} / \mathrm{c}}\right),{ }^{\circ} \mathrm{C}$ & $95-208$ & $100-200$ \\
Local heat flux $(\phi), \mathrm{MW} / \mathrm{m}^{2}$ & $5-20$ & $5-12$ \\
Experiment duration, d & $\leq 35$ & $\leq 21$ \\
\hline
\end{tabular}

${ }^{a}$ Mixed-bed demineralizer plus $\mathrm{HNO}_{3}$ additions in bypass stream.

${ }^{b}$ Calculated via Petukhov ${ }^{27}$ forced-convection heat transfer coefficient. 
temperature in the cooler stainless steel portion of the test loop) on the film growth rates could then be qualitatively explained by invoking the known solubility characteristics of iron oxide species in aqueous solutions in the coolant circulating continuously in the test loop.

c. System temperatures and heat flux were important factors that controlled the growth rate of the oxide for given coolant conditions.

d. The oxide growth for typical experiments could be described by a semiempirical rate equation with a single rate constant. The rate constant was eventually specified in terms of the local interface temperature $\left(T_{x / c}\right)$ and heat flux $(\phi)$, thus providing a correlation that could be used in conjunction with the rate equation to describe and predict oxide growth. Limited testing of the model confirmed that a reasonable predictive capability exists even for changing thermal-hydraulic conditions.

e. Spallation of the boehmite films was observed toward the end of some of the more aggressive loop experiments. Metallographic examinations of $6061 \mathrm{Al}$ and pure $\mathrm{Al}$ specimens showed that spallation was followed by the onset of severe internal reactions in the metal beneath the oxide. Such internal reactions were negligible for $8001 \mathrm{Al}^{16,26}$ and the similar ILL alloy containing $\mathrm{Ni}$ and $\mathrm{Fe}^{24}$ The presence of this reaction zone is clearly detrimental to efficient heat flow as well as structural integrity and should not be allowed to occur in reactor fuel cladding. The steady-state experiments indicated that spallation did not occur on $6061 \mathrm{Al}$ if the temperature drop across the growing oxide film was less than $119^{\circ} \mathrm{C} .{ }^{12,22}$ Moderate levels of temperature cycling were found not to induce spallation unless the films were already at or near the spallation point.

A first-principles analysis of the film growth rate curves is complicated by the fact that isothermal conditions in the boehmite film do not exist in a typical steady-state experiment in the corrosion test loop. While the interface temperature $\left(T_{x / c}\right.$, the temperature of the oxide layer in contact with the flowing coolant) does remain essentially constant during a test, the heat flux causes a temperature gradient across the growing layer. As the layer thickens, the total temperature difference across the layer increases, and the inner regions of the film and the metal specimen get hotter. As a result, the observation of a simple kinetic response (for example, parabolic growth) would be unlikely if a diffusion process were rate controlling.

Examination of the film growth kinetics for numerous experimental conditions resulted in the preliminary formulation and assignment of an appropriate semiempirical rate equation that produced the correct shape of the rate curves for the time spans typical of the ANS loop experiments.

Subsequently, the rate constants obtained on this basis were then used in the development of several working correlations. The progress of these analytical treatments was published over the course of this program. ${ }^{12,15.22}$

The integrated form of the rate equation used to fit the film growth data, generally based on leastsquares treatments of the data, is

$$
x_{t}=\left(x_{0}^{1.351}+1.351 \times k \times t\right)^{0.74} \mu \mathrm{m},
$$

where

$x_{t}=$ film thickness at time $t$, in $\mu \mathrm{m}$,

$x_{0}=$ film thickness at time $0\left(t_{0}\right)$, in $\mu \mathrm{m}$,

$k=$ rate constant, $\mu \mathrm{m}^{1.351} / \mathrm{h}$,

$t=$ time, in $h$. 
Using the above rate equation, the present correlation of choice, Correlation II, expresses the rate constant for film growth, limited to reactions in $\mathrm{pH} 5$ coolant with a range of coolant inlet temperatures $\left(\mathrm{T}_{\mathrm{ci}}\right)$ between 39 and $52^{\circ} \mathrm{C}$, as

$$
k=6.388 \mathrm{E} 7 \exp \left[-9154 /\left(T_{x / \mathrm{c}}+1.056 \times \phi\right)\right] \mu \mathrm{m}^{1.351} / \mathrm{h},
$$

where

$T_{\mathrm{x} / \mathrm{c}}=$ local interface temperature, in $\mathrm{K}$, $\phi=$ local heat flux, in $\mathrm{MW} / \mathrm{m}^{2}$.

The form of Correlation II is similar to that of the Griess Correlation, ${ }^{1,2}$ based on the film-coolant interface temperature, but modified to account for the influence of heat flux. Unlike the Kritz Correlation, ${ }^{10,11}$ which includes heat flux as a linear term in the rate constant equation, Correlation II places the heat flux term in the exponential, where it acts to modify the effective reaction temperature. Thus, the film growth rate is expressed as an Arrhenius function, a common form for many rate processes. It should also be emphasized that the interface temperature in this instance is that temperature calculated from the Petukhov forced-convection heat transfer coefficient ${ }^{27}$ using the local heat fluxes, coolant temperatures, and coolant velocities.

The rate constants determined from an appropriate group of ANS corrosion loop tests are plotted according to the tenets of Correlation II in Fig. 3.1. Only tests through CT-28 were included in making this formulation, although the results of later tests within the range of applicability were generally consistent with it. These data were obtained from experiments in which the coolant $\mathrm{pH}$ was controlled to nominally 5.0 , with variations as noted below that correlate qualitatively with their relative positions on the plot. The three data points representing each test were based upon data retrieved from the three principal thermocouple positions on the specimen. Coolant inlet temperatures for the Correlation II data set ranged from 39 to $49^{\circ} \mathrm{C}$, although most of the tests were conducted at $49^{\circ} \mathrm{C}$. In order to achieve a suitably wide range of system temperatures, the coolant velocity was varied between 9 and $25.7 \mathrm{~m} / \mathrm{s}$. Within this range, there appeared to be no independent influence of the coolant velocity upon the corrosion behavior. Additionally, these velocities produced no measurable erosion of the corrosion products, at least for the time scale and geometry involved in the experiments.

Obviously, the equation given for Correlation II, Eq. (2), is not a conservative estimator for all the data in Fig. 3.1; it does, however, represent the data in a reasonable fashion over the entire range of these variables. And, as noted above, several of the upper lines on this plot could be associated with known $\mathrm{pH}$ variations during the experiments that biased the effective $\mathrm{pH}$ over the entire experiment. The conclusion that several of the larger deviations from the prescribed Correlation II line in Fig. 3.1 resulted from poor coolant chemistry control during the test warned of the high sensitivity of the film growth process to these factors. At the highest values of the rate function (least aggressive), the tendency of the data to lie above the Correlation II curve may be subject to two additional explanations. First, the very low film growth rates for these tests were difficult to measure accurately, and their placement via a log scale magnified these errors. Second, a common characteristic of experimental Arrhenius rate representations is upward curvature of the line at low temperatures compared with extrapolation from the higher temperature data. In either instance, the present divergence is considered a minor difficulty, particularly because it occurs where the corrosion rates are extremely low and unlikely to present a serious corrosion issue.

In addition, examination of the results of tests conducted with different coolant inlet temperatures $\left(T_{\mathrm{ci}}\right)$ unexpectedly showed that this parameter was an independent variable affecting film growth. ${ }^{15,18}$ Therefore, the coolant inlet temperature could not be used indiscriminately as a tool to widen the range 


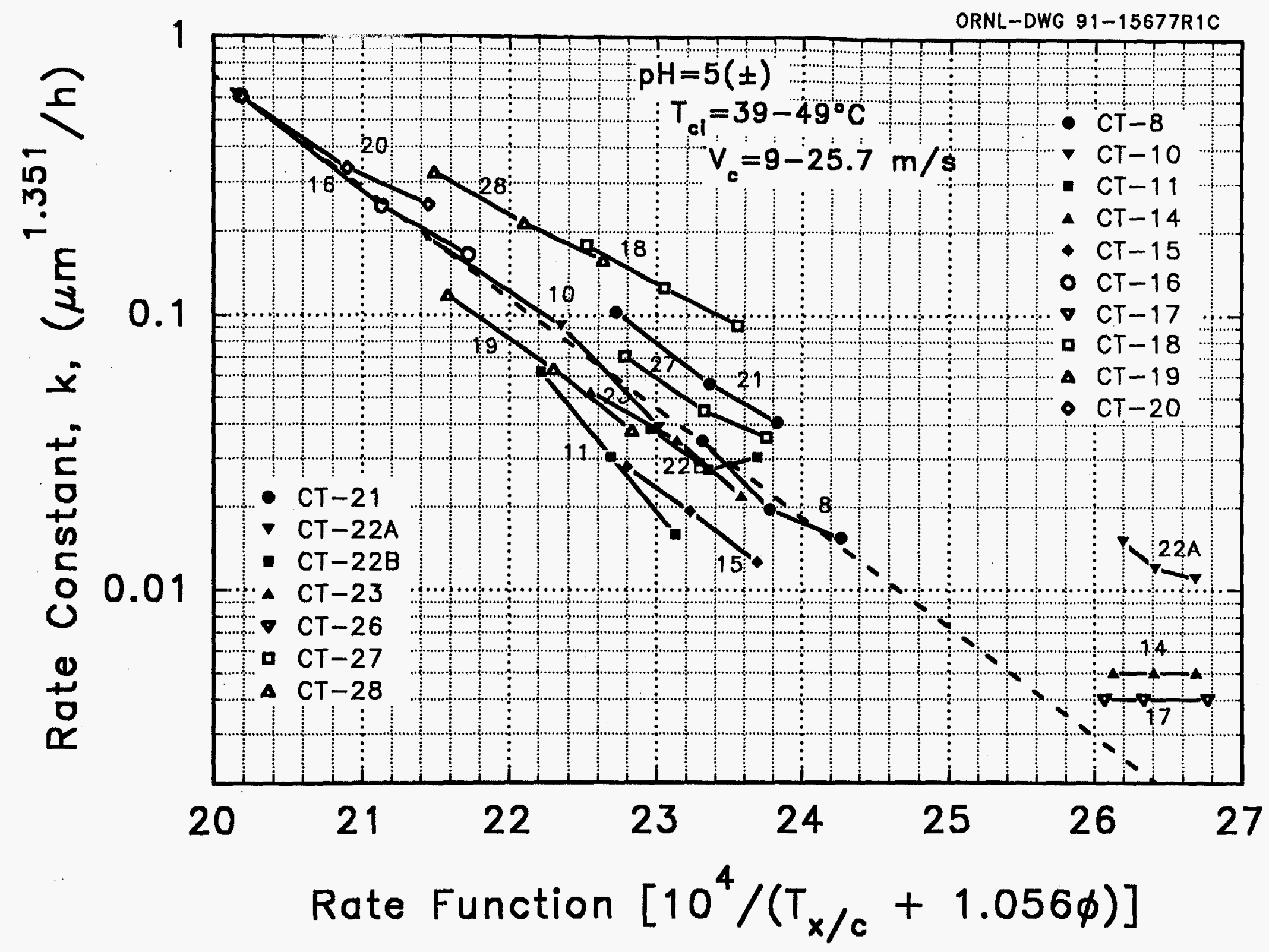

Fig. 3.1. ANS corrosion test loop results, showing grouping of measured rate constants for film growth under the specified test conditions according to Eq. (2), Correlation II. 
of interface temperatures available to our loop system for a given set of thermal-hydraulic parameters. For a given heat flux and interface temperature on the specimen, variations in coolant inlet temperature and coolant $\mathrm{pH}$ acting individually or in concert were observed to change the rate of the film growth appreciably. Figure 3.2 presents data from tests where either or both the inlet temperature and $\mathrm{pH}$ differed from those values stipulated for the Correlation II data set. This information is labeled alongside the rate data in the plot and compared with the dashed line, which represents the Correlation II values. The filled circles represent data from tests where the interface temperature $\left(T_{c i}\right)$ was greater than $55^{\circ} \mathrm{C}$; where either $\mathrm{pH}$ or $\mathrm{T}_{\mathrm{ci}}$ information is not listed, the pertinent coolant $\mathrm{pH}$ was nominally 5 , and the $\mathrm{T}_{\mathrm{ci}}$ 's were mostly $49^{\circ} \mathrm{C}$. In addition to the ANS test loop data, a recalculation of the original data set upon which the Griess Correlation ${ }^{1,2}$ was based is also presented in terms of the ANS model. Despite the lower heat flux and coolant velocity employed for the Griess data, they seem to fit the general trend and lie above the Correlation II prediction, as would be expected because of the higher coolant inlet temperatures used in the Griess experiments.

The range of the thermal-hydraulic rate function on the abscissa in this graph (and in Fig. 3.1) represents essentially the whole range of practical interest to the ANS reactor design. The location of average performance temperatures and heat fluxes proposed for the ANS reactor operation lies on the far right side of the figure; the very aggressive thermal conditions that are given by the left extreme would occur only as a result of severe off-normal conditions and uncertainty factor considerations. The middle section of the graph represents the zone of characterization of certain more realistic hot-spot and hot-streak ANS core behavior, including ever-present safety margins. The whole range of rate constants associated with this wide extent of thermal-hydraulic parameters that is predicted for film growth by Correlation II, stipulating pH 5 and $49^{\circ} \mathrm{C}$ coolant inlet temperature, is over two orders of magnitude. If these conditions were applied without relief, the resulting film growth for a given unchanging rate function then varies from superficial to virtually catastrophic in the sense of a fuel plate's surviving an extended fuel cycle.

It is important to note from Fig. 3.2 that the same range of rate constants predicted by the correlation from variations anticipated in the thermal-hydraulic rate function also occurs at constant interface temperature and heat flux by varying the coolant $\mathrm{pH}$ and interface temperatures appropriately. The maximum $\mathrm{pH}$ variation for all of the tests presented is only from 4.5 to 6.0 , clearly a very modest acidity range. The singular effect of a 20 - to 40 -degree variation in inlet temperature $\left(T_{c i}\right)$ is also apparent from the figure. Additionally, tests with $8001 \mathrm{Al}$ conducted at pH 5.4 and 6 were also consistent with the 6061 rate behavior.

To achieve appropriate bulk coolant temperatures, the initial experiments in this program all involved high coolant inlet temperatures, well above that anticipated for the actual ANS reactor. During these tests, aside from the comparison of measured rate data from separate experiments conducted with $\mathrm{pH} 4.5$ to $\mathrm{pH} 6$ coolants, the first direct dramatic indication of the impact of coolant chemistry on film growth was obtained in CTEST 7, in which the $\mathrm{pH}$ was changed several times. Figure 3.3 illustrates the changes in film growth rates at the three principal specimen positions for the first three segments of this test. In the figure, where film thickness to the 1.351 power is plotted versus time, the rate constants are proportional to the slopes of these lines [see Eq. (1)]. By making the pH changes during a single continuing experiment, while holding other test parameters essentially constant, most experimental errors that could otherwise contribute to data scatter are normalized, and the confidence in the change-in-rate observations is strengthened.

CTEST 7 was carried out with a coolant inlet temperature $\left(T_{\mathrm{ci}}\right)$ of $80^{\circ} \mathrm{C}$, an average heat flux $\left(\phi_{\mathrm{avg}}\right)$ of $11.6 \mathrm{MW} / \mathrm{m}^{2}$, and a coolant velocity $\left(\mathrm{V}_{\mathrm{c}}\right)$ of $27.5 \mathrm{~m} / \mathrm{s}$. For the first $-50 \mathrm{~h}$ of the test, the $\mathrm{pH}$ was controlled at 5.0, and these conditions combined to produce a high film growth rate, substantially higher than that predicted by Correlation II. The $\mathrm{pH}$ was then rapidly decreased to 4.5 , with all other test parameters unchanged. A corresponding drop in the rate constants of almost one order of 
ORNL-DWG 92-13600R2D

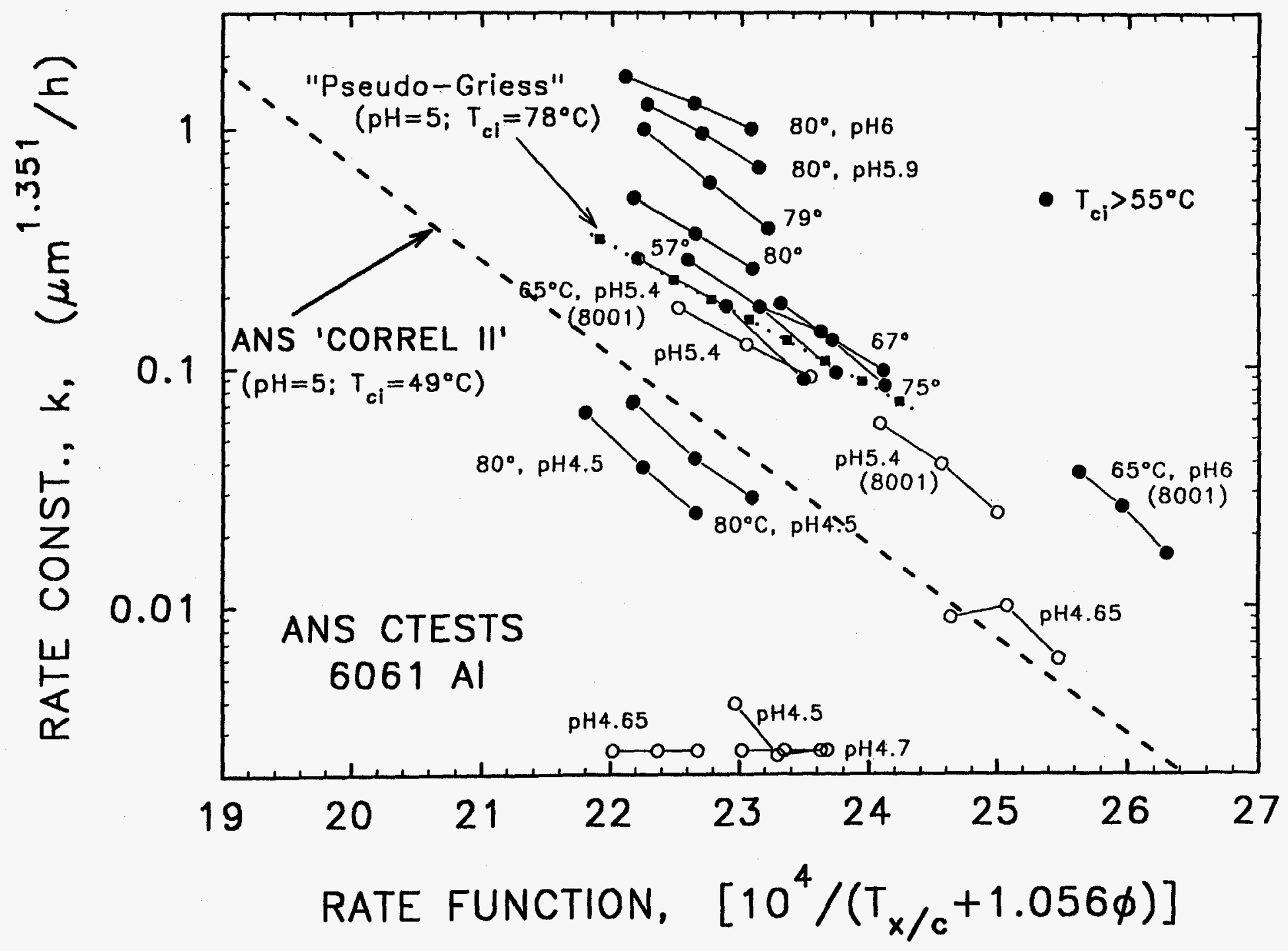

Fig. 3.2. ANS corrosion test loop experimental results, showing grouping of rate constants for oxide growth on 6061 Al compared to ANS Correlation II, suitable for coolant $\mathrm{pH}=5$ and inlet temperature 39 to $50^{\circ} \mathrm{C}$. Note influence of coolant $\mathrm{pH}$ and inlet temperature outside this range on the experimental rate constants. 


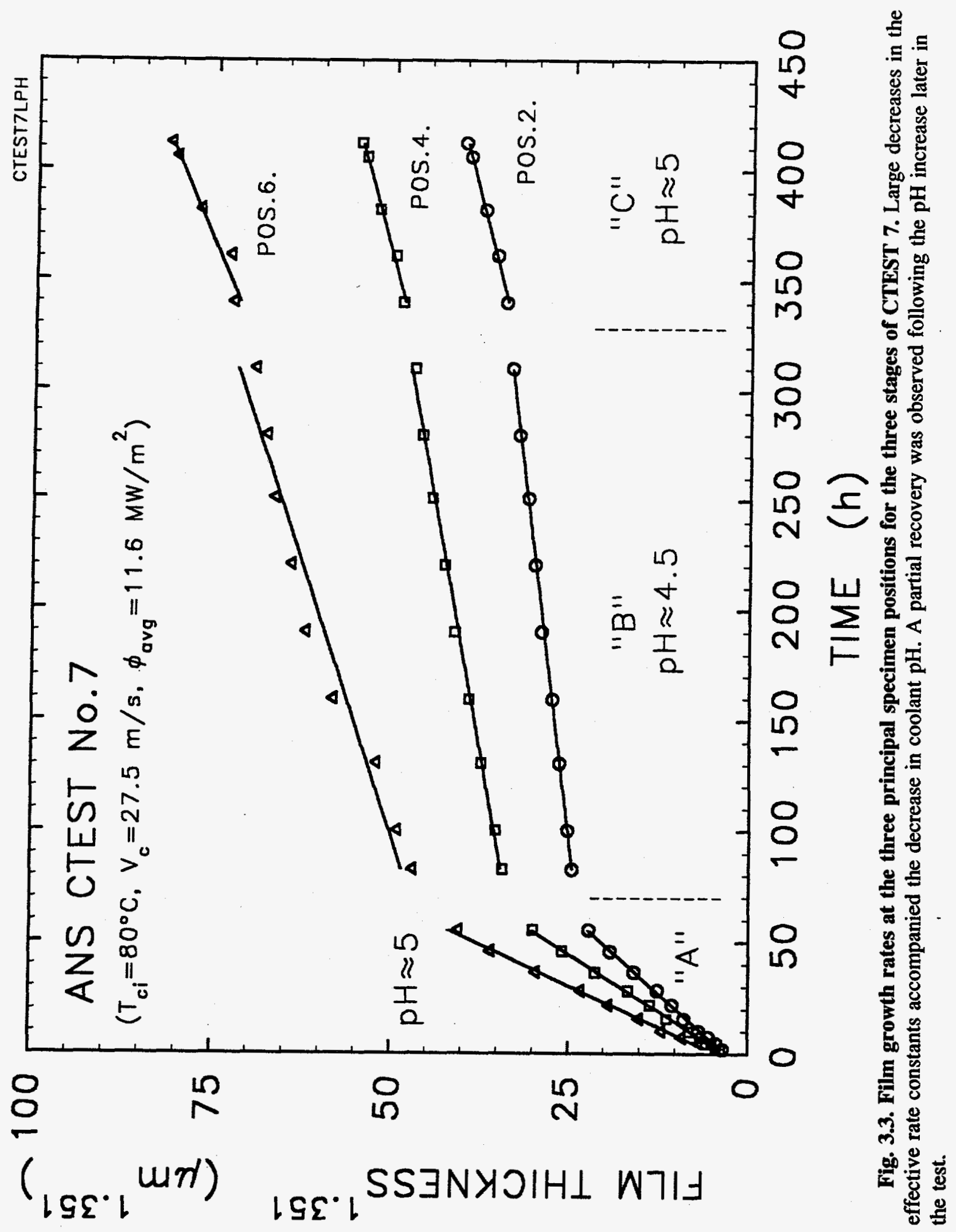


magnitude quickly followed for all three principal positions on the specimen. After an additional $250 \mathrm{~h}$ of testing at the new condition, the $\mathrm{pH}$ was returned to its original value of 5.0 and allowed to continue for an additional $100 \mathrm{~h}$. Slowly, the film growth rates along the specimen increased, not by an order of magnitude to their original values, but by a factor of approximately two. It is possible that the rates were still continuing to increase at the end of this part of the test. From this experiment, it appeared that rate changes upon decreasing coolant $\mathrm{pH}$ were more rapid (and perhaps larger) than those following an equivalent $\mathrm{pH}$ increase.

Similarly, Fig. 3.4 plots rate data for CTEST 41 , conducted at the high average heat flux of 15.3 MW/m $\mathrm{m}^{2}$ and $49^{\circ} \mathrm{C}$ coolant inlet temperature. Changing the $\mathrm{pH}$ from 5.05 to $\sim 4.8$ resulted in a factor of 5 decrease in the rate constant for film growth at all three specimen positions.

Subsequently, a similar test was conducted at comparatively low interface temperatures and heat flux, corresponding to "average" ANS reactor conditions, or "maximum" HFIR conditions. The coolant inlet temperature was constant at $49^{\circ} \mathrm{C}$, and the initial coolant velocity was $15.5 \mathrm{~m} / \mathrm{s}$. The rate curves for this test (CTEST 47) are shown in Fig. 3.5. The precise positioning of these curves is somewhat complicated by a computational problem that arose during startup and the first several hours of the test. The coolant $\mathrm{pH}$ for the initial $60 \mathrm{~h}$ was controlled at about 5.05; at this point, the $\mathrm{pH}$ was increased to 5.3 (all other parameters unchanged) without a significant alteration in the film growth rate. This lack of large response to small increases in $\mathrm{pH}$ had been noted previously in several tests where intentional increases in $\mathrm{pH}$ had caused only very slow and small increases in the kinetics. Apparently, the nature of the slowly growing film in lower $\mathrm{pH}$ environments has some degree of persistence when the $\mathrm{pH}$ is increased.

After $180 \mathrm{~h}$, while all other imposed conditions were maintained, the coolant velocity for this test was intentionally decreased from 15.5 to $11.2 \mathrm{~m} / \mathrm{s}$. Because of the poorer heat transfer, this change caused the interface temperatures $\left(T_{x / c}\right)$ along the specimen to rise by -20 to $>30$ degrees, and a sharp increase in film growth at all positions was observed. The films were allowed to grow until $290 \mathrm{~h}$, when the $\mathrm{pH}$ was lowered to 5.0 (all other parameters unchanged). As expected, the rates quickly dropped, by a factor of almost 5 , as was the case for CTEST 41 .

One additional test worthy of documentation here is CTEST 49 , conducted at relatively low heat flux and coolant velocity, where the $\mathrm{pH}$ change during the test was kept purposefully small $( - \pm 0.1 \mathrm{pH}$ unit). The test results, shown in Fig. 3.6, are similar in kind to those of CTEST 41 despite the different thermal-hydraulic conditions. In this case also, the response to the decrease in coolant $\mathrm{pH}$ is a corresponding decrease in film growth rates.

The results of the above four tests showed conclusively that coolant $\mathrm{pH}$ is an important and independent variable in determining the growth rate of the corrosion product films under the conditions of our tests. The large influence of small changes in coolant $\mathrm{pH}$ between -4.5 and 5.5 was apparent over a wide range of coolant conditions, interface temperatures, and heat fluxes. While in all cases the film growth rates were quickly decreased by decreases in $\mathrm{pH}$, increases in rate with increasing $\mathrm{pH}$ were more sluggish, suggesting that a certain persistence of the protective attributes from the low $\mathrm{pH}$ exposure lingered. The rate constants calculated for these four tests are compared to the Correlation II curve in Fig. 3.7, which shows the changes in rate constants brought about by the various changes in coolant $\mathrm{pH}$. While the Arrhenius slopes for the individual data sets seem to follow that of the correlation, the relative positions are clearly dependent upon $\mathrm{pH}$ and additionally, in the case of CTEST 7, upon the coolant inlet temperature.

Several attempts have been made to quantify the effect of coolant $\mathrm{pH}$, per se, upon the film growth behavior and rates. A number of plots and cross-plots were created that suggested ways to express the influence of the nonthermal-hydraulic parameters. In many of these, in order to simplify the presentation of the functional relationships, the rate data for each ANS CTEST was "normalized" by comparing the calculated rate constants to those predicted by Correlation $\Pi$ (where $T_{c i}=49^{\circ} \mathrm{C}$ and 


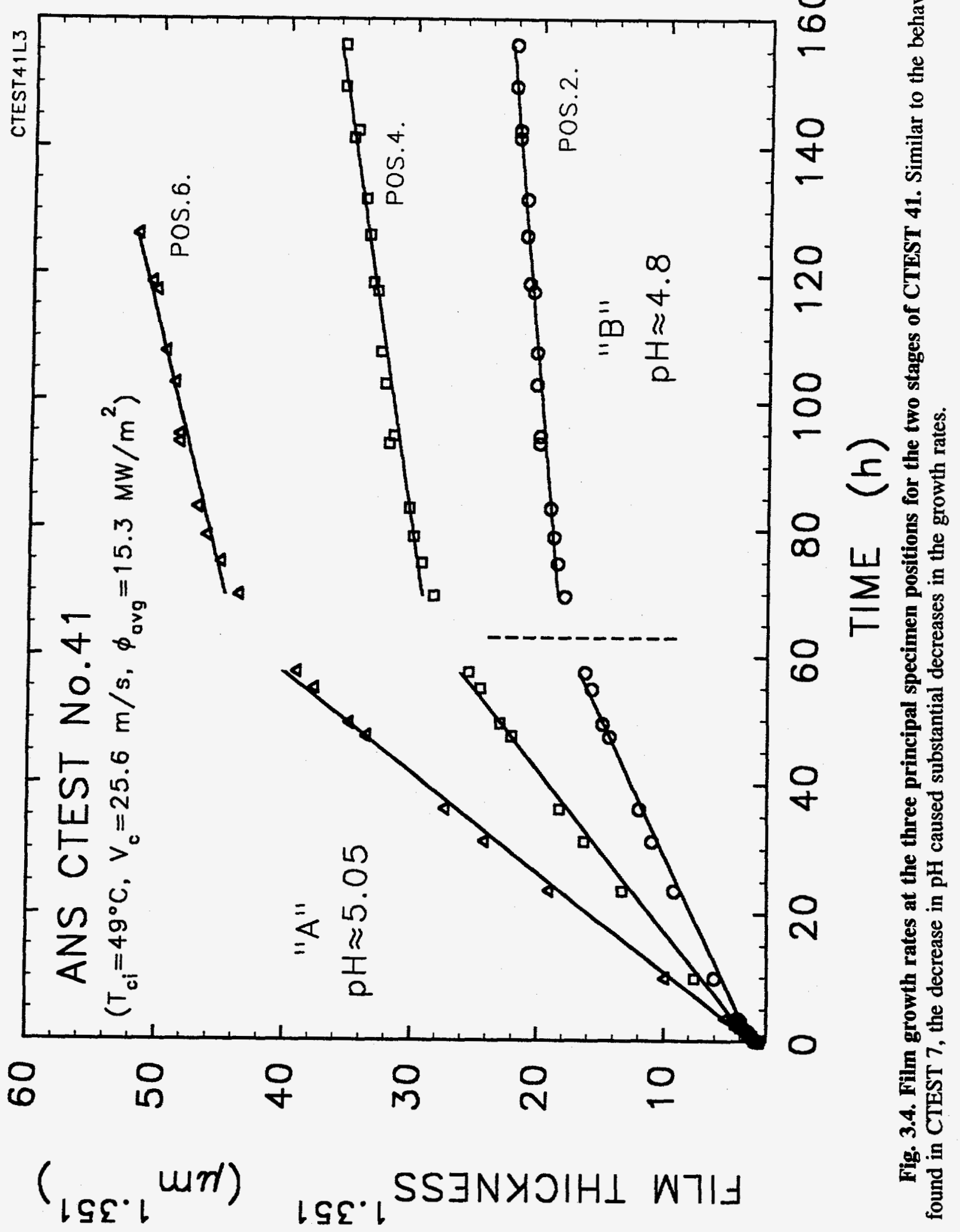




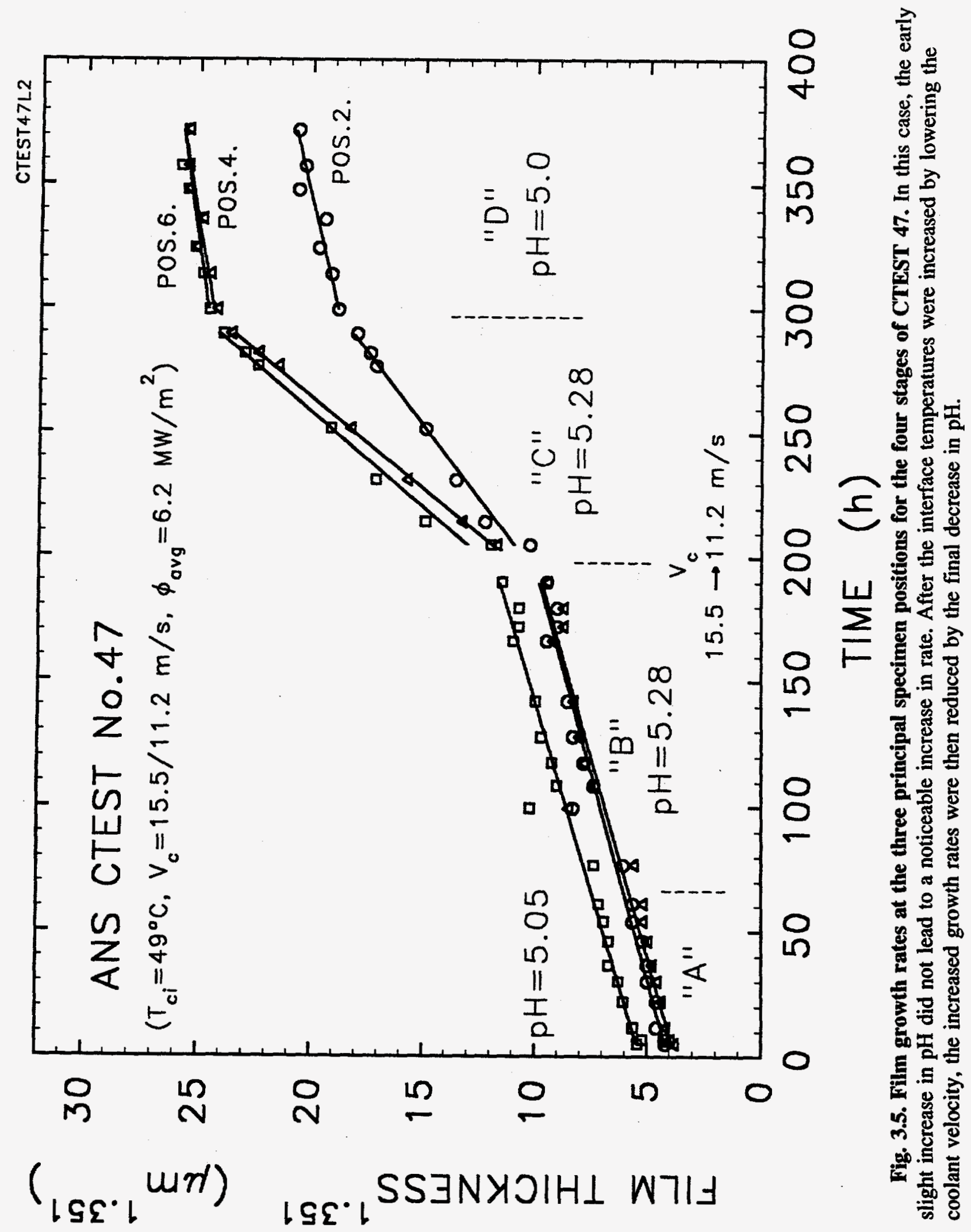




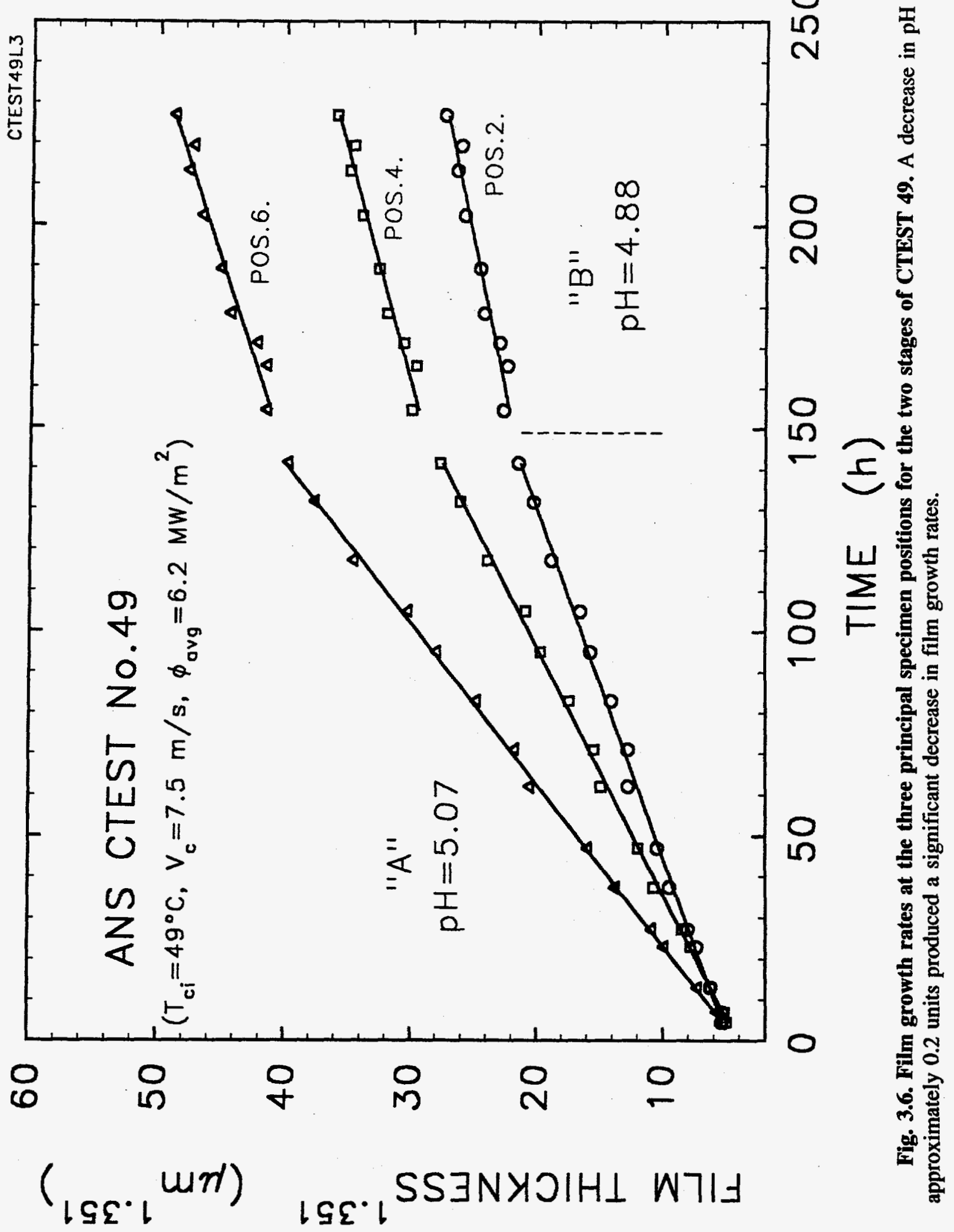




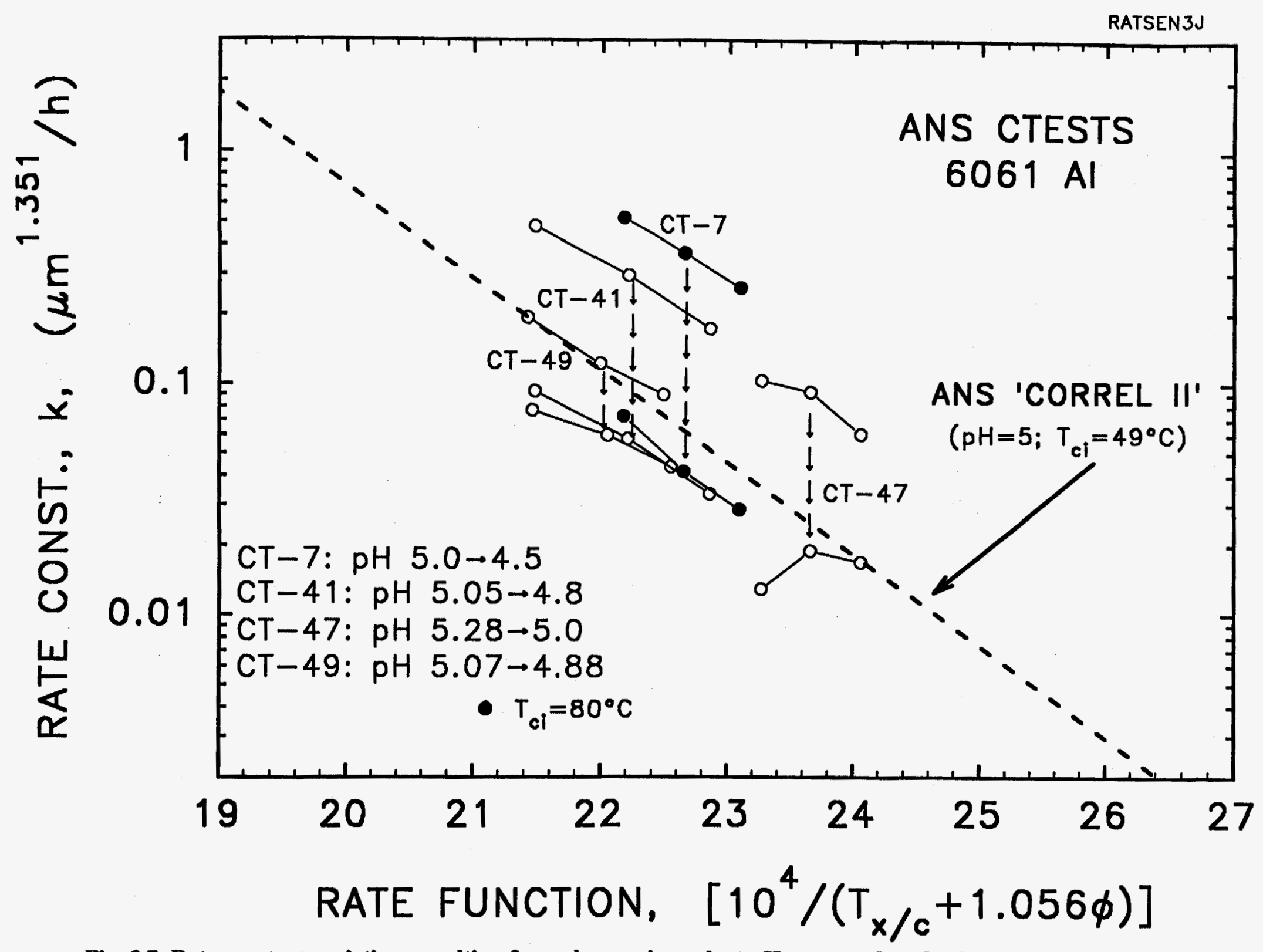

Fig. 3.7. Rate constant variations resulting from changes in coolant pH compared to the Correlation II predictions. The data of CTEST 7 would be expected to be high because of the high coolant inlet temperature $T_{c i}$ in this test. 
coolant $\mathrm{pH}=5$ are assigned) for the particular interface temperature $\left(\mathrm{T}_{\mathrm{x} / \mathrm{c}}\right)$ and heat flux $(\phi)$. Therefore, in the following plots, the basis for comparison-the "rate factor"-is the average value of the measured rate constant divided by the Correlation II prediction for the particular thermal-hydraulic conditions of the test under consideration. For simplicity and expediency, this procedure does not include any consideration of the influence of the degree of divergence from or disagreement with the 1.351 rate exponent that is assumed to apply for each case or, for that matter, of any other side issues, such as the conditions of the particular test being outside the range of the correlation's database. This is simply a method to normalize the effect of the thermal-hydraulic parameters for the sorts of comparisons being sought.

Figure 3.8 plots the rate factors for a large number of tests as a function of the measured effective coolant $\mathrm{pH}$. As indicated, these data apply only for tests conducted with coolant inlet temperatures less than $53^{\circ} \mathrm{C}$, but wide ranges of coolant velocities, interface temperatures, and heat fluxes were involved. The extended variable range and the inherent errors in the $\mathrm{pH}$ and rate factor measurements undoubtedly contribute to the large scatter in the data, particularly near $\mathrm{pH} 5$, where most of the experiments were conducted. However, it is clear that a large difference in growth rates exists for a single unit variation in the $\mathrm{pH}$. The arbitrary curve through the data has been drawn to emphasize the concept of a dramatic change in growth rate in the vicinity of $\mathrm{pH}$ 5. The data from the three applicable experiments described above where $\mathrm{pH}$ variations were imposed during the test are shown in the figure as filled data points. These data are particularly supportive of the concept that a region of high $\mathrm{pH}$ sensitivity exists, leading to striking changes in rate as the $\mathrm{pH}$ is increased from slightly less than 5 to slightly more than 5 .

Although only a few applicable data points are available, an analogous plot of rate factor vs $\mathrm{pH}$ for tests where the coolant inlet temperature $\left(T_{c i}\right)$ was nominally $80^{\circ} \mathrm{C}$ showed similar behavior. Figure 3.9 presents these data and, further, suggests that a similar sigmoidal curve is at least not an inappropriate way to express the rate dependence. The results of the two parts from CTEST 7 are shown as solid circles and agree well with the rest of the experimental data. 


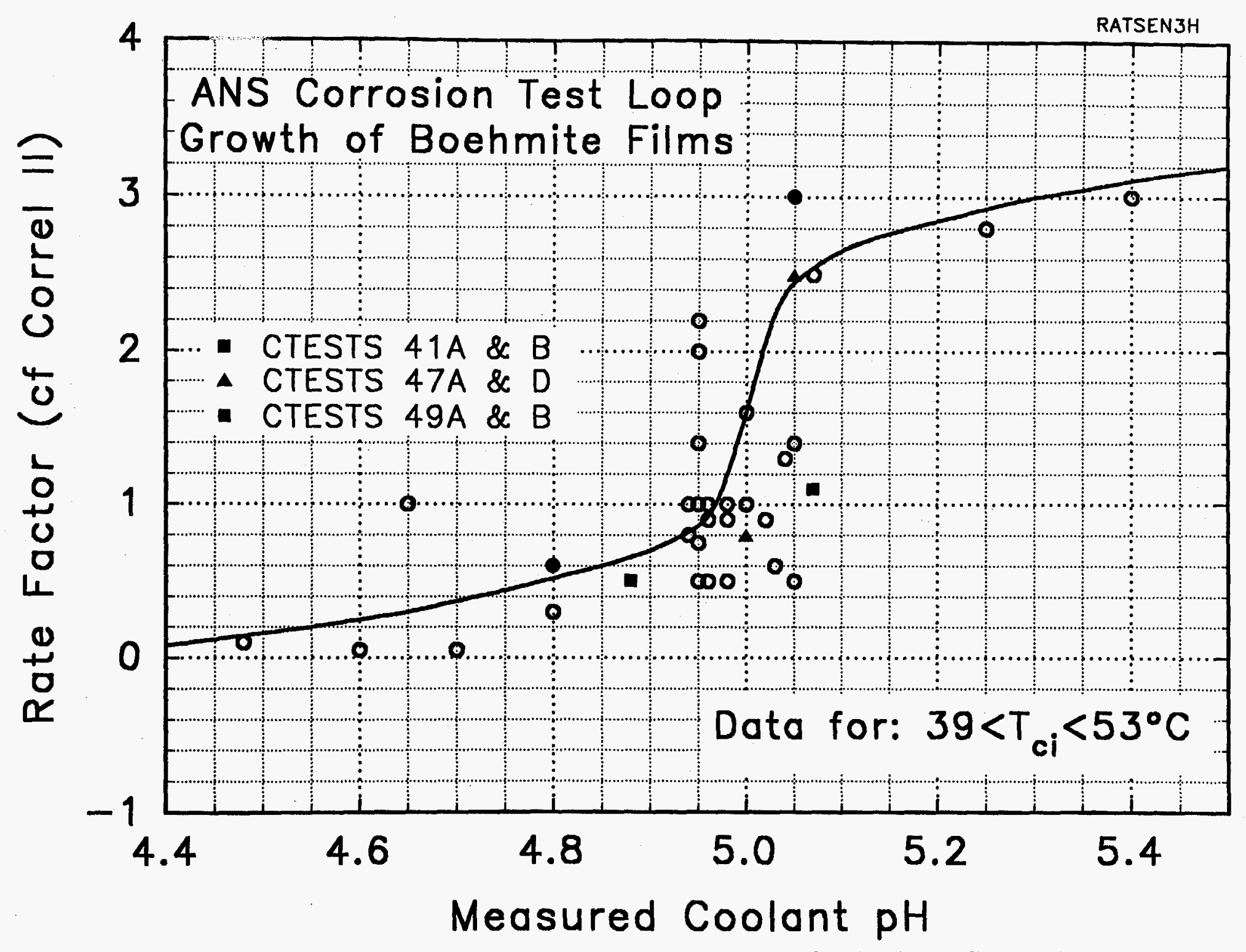

Fig. 3.8. The effect of coolant $\mathrm{pH}$ on the relative oxide growth rate constants for aluminum alloy specimens exposed in the ANS corrosion test loop with coolant inlet temperatures $\left(T_{a}\right)$ less than $53^{\circ} \mathrm{C}$. Solid data points are from experiments where pH changes were imposed during the test. 

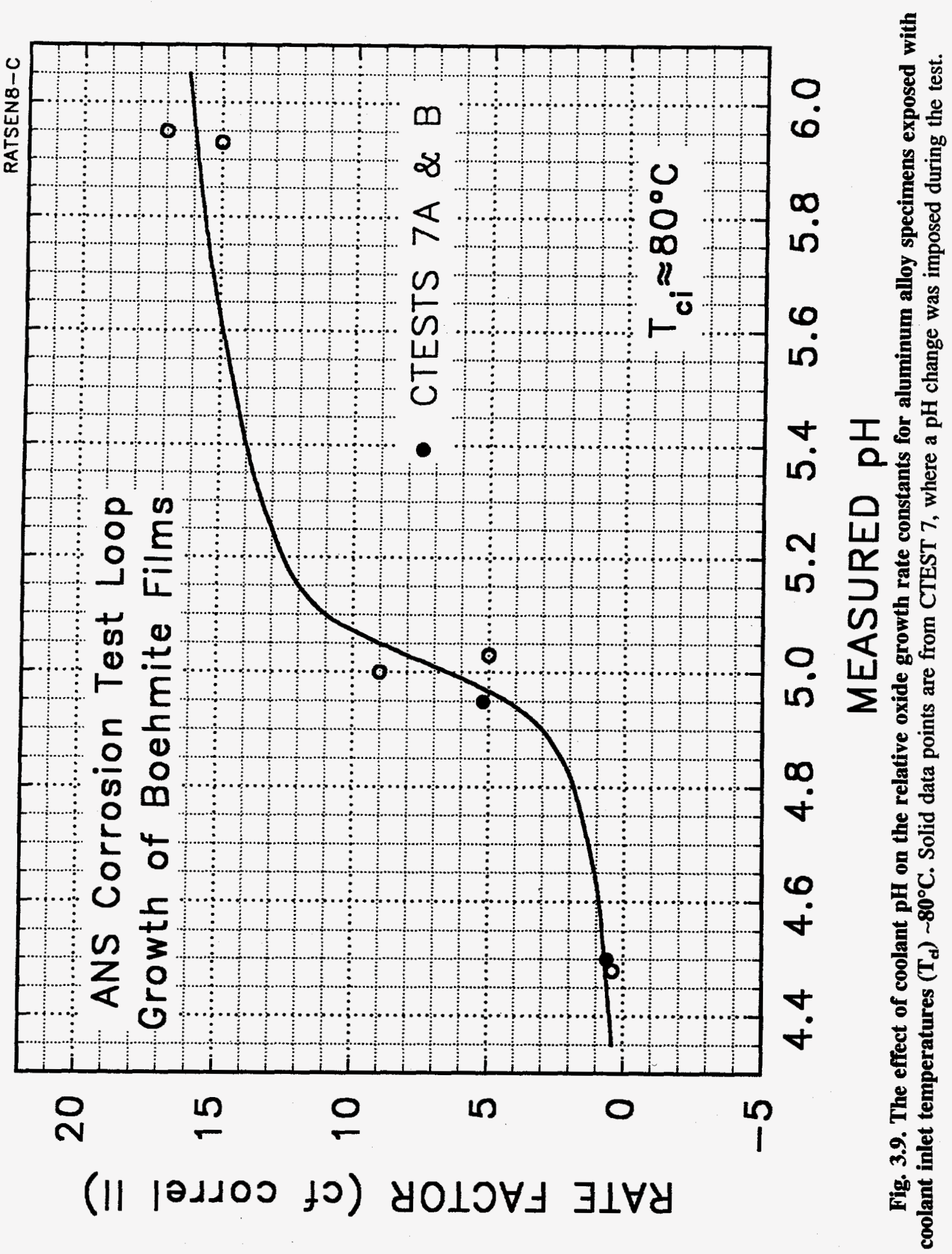



\section{DISCUSSION}

Boehmite $\left(\mathrm{Al}_{2} \mathrm{O}_{3} \cdot \mathrm{H}_{2} \mathrm{O}\right)$ was consistently the predominant species composing the corrosion product films formed during experiments in the corrosion test loop. This identification was achieved mostly through X-ray pattern analyses and comparisons but was often complicated by the small amounts of material present and by the small grain size of the products (which caused line broadening). In addition, small peaks resulting from bayerite $\left(\mathrm{Al}_{2} \mathrm{O}_{3} \cdot 3 \mathrm{H}_{2} \mathrm{O}\right)$ were sometimes found in the patterns, while numerous weak lines in the background remained unidentified. It is probable that a poorly crystalline form, "pseudoboehmite," also existed and that this was more common at the cooler inlet end of the specimen. Generally, the heat fluxes were sufficiently high in the present set of tests to ensure that boehmite was the stable product at the reaction temperature. The boehmite films formed on the corrosion test specimens were often transparent to the naked eye, always adherent and, at least for films thicker than $-5 \mu \mathrm{m}$, reasonably uniform in thickness on a microscopic scale. Thus, the morphology and structure of the corrosion product, at least prior to spallation, could be described in simple terms.

Early in the ANS corrosion test program, however, it was apparent that the visual appearance of the test specimen after exposure depended sensitively upon the coolant $\mathrm{pH}$ as well as upon the thermal-hydraulic parameters of the test. Even the coolant inlet temperature was found to be significant. Specimens could appear silvery gray (metallic) with little visible evidence of a boehmite product film as noted above, or they could exhibit a gold-brown color ranging from light straw at the coolant inlet end to deep gold and brown at the exit end. Coolant pH's greater than 5 and coolant inlet temperatures greater than $60^{\circ} \mathrm{C}$ favored the former description.

The very color of many of the surfaces for tests with $\mathrm{pH} 5$ and coolant inlet temperatures less than $50^{\circ} \mathrm{C}$ suggested the presence of iron or iron oxides and, when the electron microprobe was used to examine cross sections of the specimens, this fact was confirmed. The distribution of iron in the boehmite films on $6061 \mathrm{Al}$ and the other alloys was interesting and significant in that it appeared to be concentrated only in the outermost micron or two of a film that was perhaps 15 or $20 \mu \mathrm{m}$ in total thickness. ${ }^{15,16}$ Although $6061 \mathrm{Al}$ contains as much as 0.25 at. \% Fe, there was no evidence of a diffusion profile through the film that might suggest that the alloy itself was the source of the Fe in the outermost regions of the film. Instead, maximum Fe concentrations above 10 at. $\%$ have been measured in the outer layer of the boehmite film, hence the term "Fe-rich layer," which has been discussed in previous reports.

The fact that the Fe-rich layer always remained on the outermost surface of the growing boehmite film without an obvious diffusion source has several interesting ramifications. First, this morphology implied that the source of the Fe was external to the specimen, e.g., the stainless steel piping in the remainder of the loop. Second, the fact that the Fe remained at the outer surface rather than becoming smeared or partially buried during film growth implied that the mechanism of oxide growth involves predominantly anion diffusion. In a real sense, the Fe layer serves as a classical "marker" for this diffusion determination. It has been speculated that either $\mathrm{OH}^{-}$or $\mathrm{O}^{-}$ions are the likely diffusing species with the hydroxyl ion being the most likely because it could supply the necessary hydrogen for boehmite growth at the oxide-metal interface, with some left over to be involved perhaps in some aspect of the spallation and/or internal reaction phenomena. Finally, the fact that substantial quantities of Fe accumulate on the surface during the test despite the observation that some of the reacting aluminum (perhaps as high as $30 \%$, at least when little or no Fe-rich layer is present ${ }^{2}$ ) ends up in the coolant, implies that $\mathrm{Al}$ also diffuses through the Fe-rich layer to go into solution in the coolant. Thus, to be consistent with all the observations, it appears that some level of both anion and cation diffusion probably takes place and that a complete description of the film growth mechanism may be very complicated. 
The characterization of the extent of the Fe-rich layer, based largely upon electron microprobe examinations of selected specimens, remains incomplete and only semiquantitative: (1) the iron is concentrated in the outer tenth or so of the film regardless of its thickness, and (2) the maximum Fe concentration recorded by the probe can vary by more than an order of magnitude, up to $>10$ at. $\%$. For the record, Table 4.1 presents a compilation of the electron probe results, giving the maximum measured Fe concentration in the Fe-rich layer along with other test attributes for the group of specimens selected for examination. Since the probe has an effective spot diameter of $-1 \mathrm{pm}$ and the traverses were accomplished by a programmed raster in 1- $\mu \mathrm{m}$ steps, the possible error or variation in the maximum $\mathrm{Fe}$ concentration can be large and increases with decreasing layer thickness. No attempt has been made in Table 4.1 to account for this effect in the recorded Fe concentration values. Although the association between film growth rates and the maximum iron concentration is certainly not as consistent or as striking as the $\mathrm{pH}$ effect, it appears that some feature of this layer does serve to impede the growth of the boehmite, and its presence is thus important from a kinetics standpoint. Earlier, it was proposed that the Fe layer served as a diffusion barrier, ${ }^{15}$ thus affecting film growth rates. While it is probable that this mechanism is still a logical, simplistic description, there is a clear need for additional details and a deeper understanding.

The precise mechanism by which $\mathrm{Fe}$ is transferred from the stainless steel components of the loop system is not known. Nonetheless, given the fact that the corrosion test loop is constructed and operated to emulate the primary coolant system of the reactor, it is entirely possible that this sort of mass transport would also occur in-reactor. Some in-reactor evidence of this phenomenon has been reported (for example, in Ref.4), although its ramifications in the present context were not discussed.

Therefore, despite the qualitative nature of some of the observations and interpretations, a most important result of these tests has been the realization that the corrosion and film growth on aluminum alloys under the given test conditions are system dependent and cannot be considered in an isolated manner independent of the loop surroundings. Indeed, the primary coolant system of the test loop (and the reactor coolant system as well) must be considered in its chemical context. High-purity water can be very active chemically, particularly when operating between temperature extremes in a coolant loop circuit. When different materials of construction are involved, such as the $\mathrm{Al}$ specimen and the stainless steel piping, added complications arise. Some level of mass transport, similar in kind to that observed in heat-transfer loop systems involving liquid metal coolants, is therefore to be anticipated. In the loop system under discussion here, water temperatures and solubilities of the major participants are relatively very low, but the principles leading to mass transport between the temperature extremes of the loop are the same.

One unusual feature of the ANS corrosion loop test system is that iron or an iron oxide species was observed to be deposited on the hot surface of the specimen, atypical of mass transport in most systems driven by solubility-temperature considerations. A possible explanation for this phenomenon based largely on circumstantial or indirect evidence, but consistent with the imposed conditions and observations, is as follows. Many transition metal oxide species in aqueous solutions exhibit increased solubility with increasing temperature for solution $\mathrm{pH}$ greater than about 6 . At each temperature, the solubility exhibits a distinct minimum with varying $\mathrm{pH}$, generally at slightly acid conditions. As the solution temperature increases, the $\mathrm{pH}$ at which the minimum occurs is shifted to slightly lower values. The crossover where solubility at the higher temperature is lower results in a transition from "normal" to "retrograde" solubility as the $\mathrm{pH}$ is decreased to a certain value, which depends upon the thermodynamics of the metal species-water system. In the "retrograde" regime, the solubility decreases as the temperature is increased. A schematic drawing illustrating this behavior is presented in Fig. 4.1, which gives inferred solubility values typical of iron (and chromium) oxides in aqueous solutions as a function of the solution $\mathrm{pH}$. It should be emphasized that these curves, as drawn, are conceptually accurate but lack a completely quantitative foundation. Nevertheless, they are useful in explaining the 
Table 4.1. Electron microprobe results: Fe-rich layer

\begin{tabular}{|c|c|c|c|c|c|c|c|}
\hline $\begin{array}{l}\text { ANS CTEST } \\
\text { number/position }\end{array}$ & $\begin{array}{c}\text { Coolant } \\
\mathrm{pH}\end{array}$ & $\begin{array}{c}\text { Inlet } \\
\text { temperature } \\
\left({ }^{\circ} \mathrm{C}\right)\end{array}$ & $\begin{array}{l}\text { Interface } \\
\text { temperature } \\
\left({ }^{\circ} \mathrm{C}\right)\end{array}$ & $\begin{array}{l}\text { Duration } \\
\text { (h) }\end{array}$ & $\begin{array}{l}\text { Film } \\
\text { thickness } \\
\text { (jm) }\end{array}$ & $\begin{array}{c}\text { Surface } \\
\text { appearance }^{a}\end{array}$ & $\begin{array}{l}\text { Maximum } \\
\text { measured Fe } \\
\text { concentration } \\
\text { (at. \%) }\end{array}$ \\
\hline CT-10/4 & $5.0 \pm 0.1$ & 39 & 158 & 280 & 15 & $g d-b r$ & 0.8 \\
\hline CT-12/2 & $5.95 \pm 0.15$ & 80 & 148 & 53 & 21 & met $\mathrm{gr}$ & 0.1 \\
\hline CT-15/4 & $4.95 \pm 0.1$ & 49 & 144 & 575 & 7 & med gd & 2.7 \\
\hline CT-16/4 & $5.0 \pm 0.1$ & 49 & 181 & 57 & 11 & met gr-gd & 0.2 \\
\hline CT-18/4 & $5.35 \pm 0.3$ & 49 & 154 & 510 & 23 & dk br & 2.5 \\
\hline CT-19/4 & $4.95 \pm 0.15$ & 49 & 162 & 500 & 15 & $g d-b r$ & 9.9 \\
\hline CT-20/4 & $5.0 \pm 0.05$ & 49 & 192 & 117 & 17 & It br & 2.1 \\
\hline CT-26/6 & $4.5 \pm 0.05$ & 49 & 149 & 450 & 4 & $\mathrm{dk}$ br & 2.1 \\
\hline CT-27/2 & $4.95 \pm 0.05$ & 49 & 135 & 510 & 14 & gd & 2.6 \\
\hline CT-27/6 & $4.95 \pm 0.05$ & 49 & 152 & 510 & 14 & $g d-b r$ & 15.1 \\
\hline CT-29/6 & $4.95 \pm 0.1$ & 49 & 172 & 1225 & 15 & br-bl & 19.8 \\
\hline CT-30/6 & $5.35 \pm 0.2$ & 49 & 138 & 1293 & 29 & bl & 6.0 \\
\hline CT-31/6b & $5.05 \pm 0.2$ & 50 & 163 & 1220 & 15 & br-gr & 8.7 \\
\hline CT-32/4 $4^{b}$ & $6.0 \pm 0.5$ & 65 & 111 & 1344 & 16 & met gr & 0.2 \\
\hline CT-32/6 & $6.0 \pm 0.5$ & 65 & 116 & 1344 & 21 & met $\mathrm{gr}$ & 0.3 \\
\hline CT-33/6 & $5.4 \pm 0.2$ & 65 & 172 & 740 & 60 & br & 6.5 \\
\hline CT-34/4 & $5.05 \pm 0.1$ & 49 & 142 & 334 & 17 & It gd & 0.4 \\
\hline CT-35/2 & $4.95 \pm 0.1$ & 49 & 138 & 640 & 11 & It $\mathrm{gd}$ & 0.4 \\
\hline$C T-35 / 4$ & $4.95 \pm 0.1$ & 49 & 149 & 640 & 15 & gd & 7.2 \\
\hline CT $-36 / 4^{c}$ & $4.95 \pm 0.1$ & 49 & 139 & 554 & 12 & It gd-br & 1.0 \\
\hline $\mathrm{CT}-37 / 2^{b}$ & $4.95 \pm 0.1$ & 49 & 134 & 523 & 11 & met $\mathbf{g x}$ & 0.3 \\
\hline CT-37/6 & $4.95 \pm 0.1$ & 49 & 155 & 523 & 28 & gd-br & 6.0 \\
\hline CT-38/2 & $4.94 \pm 0.1$ & 49 & $133 / 146$ & $502 / 720$ & 4 & It gd & 3.8 \\
\hline CT-38/6 & $4.94 \pm 0.1$ & 49 & $146 / 161$ & $502 / 720$ & 5 & gd-br & 10.0 \\
\hline CT-43/6 & $5.0 \pm 0.1$ & 49 & $152 / 166$ & $380 / 670$ & 28 & bl-br & 7.5 \\
\hline
\end{tabular}

Nomenclature: $\mathrm{tt}$ - light, med = medium, $\mathrm{dk}$ - dark, gd - gold, br - brown, bl - black, met = metallic, gr - gray.

b8001 Al specimen.

Ture Al specimen.

¿1100 Al specimen.

ILL alloy specimen. 


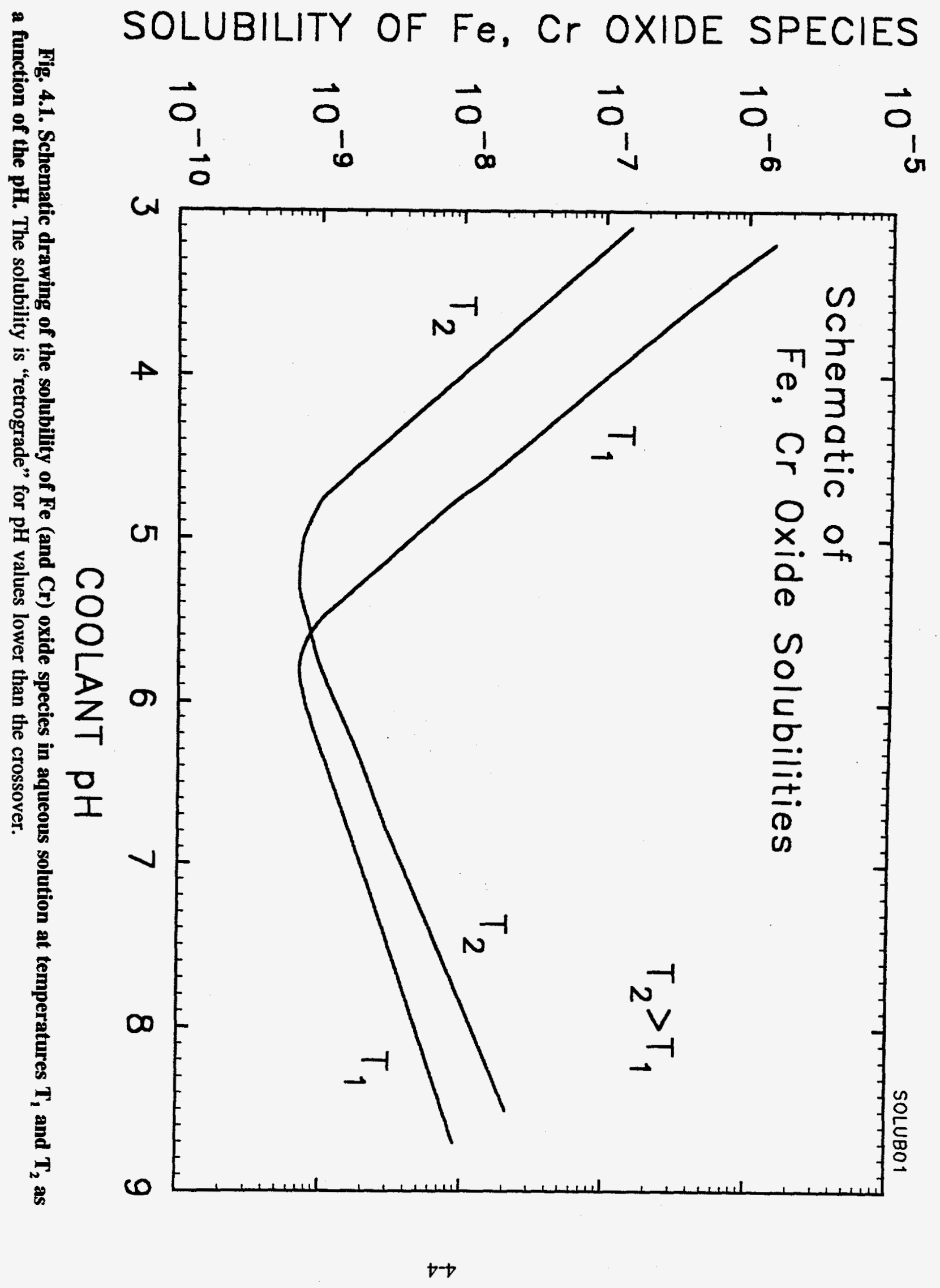


concept of retrograde solubility and the conditions under which it occurs. Similar curves have been reported relative to the solubility of magnetite (iron oxide) and other oxides. ${ }^{28,29}$ Quantitative high sensitivity mass-spectrographic analyses of the coolant water in our test loop were difficult because of the generally high purity. However, iron concentrations ranging from undetected to less than $100 \mathrm{ppb}$ were measured, with the higher levels found in the more acid coolants. Details of these measurements have been reported. ${ }^{16}$

In the ANS corrosion test loop, as well as the proposed ANS reactor, the coolant water is heated as it passes through the specimen (core), interacting with the specimen surface (fuel cladding). The surface of the specimen is significantly hotter than the bulk coolant water because of the high heat flux. The coolant water leaving the specimen travels in 304L stainless steel tubing (with oxide-covered walls) to the heat exchanger, where the generated heat is removed. The coolant is then pumped through the additional $304 \mathrm{~L}$ loop plumbing, where it is reintroduced into the specimen at the coolant inlet temperature $\left(T_{c i}\right)$. The heat exchanger is controlled to keep $T_{c i}$ constant for the entire experiment. $T_{c i}$ is considered to be representative of the minimum water temperature in the stainless steel parts of the loop; the hottest positions are within the specimen channel, where the coolant is heated, and particularly at its contact with the hot surfaces where the temperature is increased to the interface temperature $\left(\mathrm{T}_{\mathrm{x} / \mathrm{c}}\right)$.

In Fig. 4.1, the curves labeled $T_{2}$ and $T_{1}$ have been drawn to represent the solubility dependence for the extremes of the loop temperatures, $T_{x / c}$ (and/or $T_{c}$ ) and $T_{c j}$. In the plot, a "normal" solubility temperature dependence is proposed to exist for coolant $\mathrm{pH}$ above -5.5 , and therefore in this region no tendency for iron oxide to be transported from the steel surfaces to the aluminum would exist. For $\mathrm{pH}$ below 5.5, some degree of "retrograde" solubility exists, and a driving force for iron transfer to the aluminum surface arises. While it is unlikely that equilibrium concentrations would be achieved in such a flow system, the general trends would be present. For example, "cold" water having a relatively high concentration of iron oxides would enter the specimen flow channel. As the water is heated in the channel, the bulk temperature might or might not get hot enough to lead to a general precipitation; however, the interface temperature is much hotter and would be expected to deliver the precipitate at or near the boehmite surface. The increasing bulk water temperatures and interface temperatures along the specimen, according to the tenets of retrograde solubility, would then account for the observed color variations and probe measurements that indicate increasing iron concentration toward the hot end of the specimen. Similarly, for tests conducted at nominally pH 6, no iron transport to the specimen would be expected, and extremely small values were observed. As the solubility curves in Fig. 4.1 are drawn, they become parallel at $\mathrm{pH}$ 's below -4.7 , signifying that below this $\mathrm{pH}$ no extra driving force via a solubility difference for transfer would accrue. If Fe transport were involved in the film growth kinetics, this model of the behavior would support the existence of a narrow range of $\mathrm{pH}$ in which the growth rates would change appreciably.

The experimental observations concerning the effect of coolant temperatures (including inlet temperature), coolant chemistry, coolant velocity, and heat flux upon film growth kinetics are in good qualitative agreement with this hypothesis, but its acceptance is recognized to be in need of further phenomenological evidence and additional theoretical support. In spite of the lack of a completely explicit model, a principal implication of these results is that this sort of mass transport is likely to occur in the reactor primary coolant system, and that corrosion of the fuel cladding will be affected in a manner similar to that found in the ANS loop tests.

As noted previously, the results of the ANS corrosion testing are consistent with the historic inreactor observations concerning the importance of water chemistry to the performance of the primary coolant system and to film buildup in the reactor core. Good control of the coolant at slightly acid levels has become an accepted specification for operation of many reactor systems. However, because the ANS involved a reactor moderated and cooled with heavy water, the possibility was noted that the 
optimum acidity $(\mathrm{pH})$ for reactor operation might be different from that in light water systems. The ANS corrosion program was scheduled to test this prospect by conducting several scoping tests using heavy water $\left(\mathrm{D}_{2} \mathrm{O}\right)$ coolant in the ANS test loop, but the project was terminated first.

The objective of the latter series of tests was to determine the particular ionic species important in film growth on aluminum. It is known that the dissociation constants of $\mathrm{H}_{2} \mathrm{O}$ and $\mathrm{D}_{2} \mathrm{O}$ are different (for example, at $25^{\circ} \mathrm{C}$ in mole/liter units, $\mathrm{K}_{\mathrm{H}_{2} \mathrm{O}}=1 \mathrm{E}-14$ and $\mathrm{K}_{\mathrm{D}_{2} \mathrm{O}}=1.365 \mathrm{E}-15$, calculated from Refs. 30 and 31 ). Given this fact and assuming similar solubility considerations, it follows that if the concentration of hydrogen $\left(\mathrm{H}^{+}\right)$ions or deuterium $\left(\mathrm{D}^{+}\right)$ions controls the film growth behavior on aluminum in light water and heavy water coolant systems, the required or optimum $\mathrm{pD}$ for the heavy water coolant would be the same as the $\mathrm{pH}$ value assigned for light water. If, on the other hand, the concentration of the negative ions $\left(\mathrm{OH}^{-}\right.$or $\left.\mathrm{OD}^{-}\right)$controls film growth, then the different dissociation characteristics come into play, and the $\mathrm{pD}$ for optimum behavior would be different from the $\mathrm{pH}$. The results of the tests to date do not address this problem and, with the cancellation of the ANS project, the heavy water data will not be available to make this determination directly. However, if and when the problem again arises, such differences should be investigated.

Suppose it is desired to operate a heavy water coolant system according to coolant conditions optimized by light water corrosion results and considerations. For example, suppose that the optimum $\mathrm{pH}$ for the coolant in a light water circulating system was chosen to be 4.7 , measured at $25^{\circ} \mathrm{C}$ and produced by the controlled addition of $\mathrm{HNO}_{3}$ to the demineralized coolant water (a possible compromise between lowering film growth on aluminum and the stimulation of stress corrosion cracking in stainless steel). Then, using conventional notation and assumptions involving dilute solutions:

$$
\begin{aligned}
{\left[\mathrm{H}^{+}\right] } & =1 \times 10^{-4.7}(=1.995 \mathrm{E}-5) \mathrm{mol} / \mathrm{L}, \\
{\left[\mathrm{OH}^{-}\right] } & =1 \times 10^{-9.3}(=5.012 \mathrm{E}-10) \mathrm{mol} / \mathrm{L} .
\end{aligned}
$$

Case I, for cation control: In a heavy water coolant similarly acidified with $\mathrm{DNO}_{3}$, the $\mathrm{pD}$ would simply be identical to the $\mathrm{pH}$ (equal cation concentrations). The measurement of $\mathrm{pD}$ in heavy water solutions is equivalent to a $\mathrm{pH}$ measurement, and techniques and equipment exist to perform that task. A common approach in a heavy water system is to use a standard $\mathrm{pH}$ meter appropriately calibrated with light water solutions. Using such a $\mathrm{pH}$ meter system in a heavy water solution, the $\mathrm{pD}$ is given by (Ref. 32):

$$
\mathrm{pD}=\mathrm{pH}_{\mathrm{a}}+0.408
$$

where

$\mathrm{pD}=-\log \left[\mathrm{D}^{+}\right]$(analogous to $\mathrm{pH}$ ),

$\mathrm{pH}_{\mathrm{a}}=$ value measured with light water meter.

Thus, in our example that assumes equal cation concentrations,

$$
\begin{aligned}
& \mathrm{pD}=4.7, \text { or } \\
& \mathrm{pH}_{\mathrm{a}}=4.292 .
\end{aligned}
$$


Case $\Pi$, for anion control: In a heavy water coolant, the $\mathrm{pD}$ is derived from that value for which $\left[\mathrm{OH}^{-}\right]=\left[\mathrm{OD}^{-}\right]$. For $\mathrm{pH}=4.7,\left[\mathrm{OH}^{-}\right]=1 \times 10^{-9.3}$, and therefore:

$$
\begin{aligned}
{\left[\mathrm{OD}^{-}\right] } & =1 \times 10^{-9.3}, \text { and } \\
{\left[\mathrm{D}^{+}\right] } & =\left(1.365 \times 10^{-15}\right) /\left(1 \times 10^{-9.3}\right)=1.995 \mathrm{E}-5 \mathrm{~mol} / \mathrm{L} .
\end{aligned}
$$

Thus,

$$
\begin{aligned}
\mathrm{pD} & =5.565 \text { (generally, for anion control, } \mathrm{pD}=\mathrm{pH}+0.865) \text {, or } \\
\mathrm{pH}_{\mathrm{a}} & =5.157
\end{aligned}
$$

From these typical-case calculations, the optimum $\mathrm{pD}$ could vary by almost a whole unit depending upon which ion concentration controls the film growth rates. As the data in Fig. 3.8 attests, this probably would not be a trivial matter at least for the more aggressive corrosion conditions, and this aspect should come under consideration in a complete design analysis for heavy water coolants.

It is recognized that all aspects of the influence of coolant water chemistry were not addressed in this experimental program. The correlation of the results and many of the analyses are empirical in nature and may apply only within the intended range of variables. Additionally, direct extrapolation of the results from the corrosion test loop to a real reactor primary system requires the acceptance of many assumptions that only in-reactor data and operational histories can address. While the experimental loop system was designed to model many aspects of the reactor system, there are clearly many potentially important differences. The results should be interpreted and utilized accordingly. Had the ANS been built, closure was to be accomplished by comparison of the correlations with measurements from spent core assemblies. 



\section{SUMMARY}

1. Specimens of $6061 \mathrm{Al}$ (and other aluminum alloys) were exposed at high heat fluxes and coolant velocities in a corrosion test loop designed to simulate as much as possible the proposed ANS reactor primary coolant system. The data for exposure in nominally $\mathrm{pH} 5$ coolant were utilized to develop a correlation for predicting oxide film growth on aluminum as a function of its thermalhydraulic history.

2. The coolant $\mathrm{pH}$, slightly acid via $\mathrm{HNO}_{3}$ additions, was found to affect film growth significantly. In addition, the coolant inlet temperature surprisingly was found to be an independent variable. Increases in coolant $\mathrm{pH}$ (from its basis level of 5.0) and increases in coolant inlet temperature (from its basis level of $49^{\circ} \mathrm{C}$ ) each resulted in an increased film growth rate.

3. Tests in which the coolant $\mathrm{pH}$ was varied from 4.5 to 6 showed a large effect on the film growth behavior and film composition. Experimental results showing an abrupt change in growth rate between about $\mathrm{pH} 4.9$ and 5.1 were presented. A second set of data for tests conducted with a higher range of coolant inlet temperatures produced a similar result.

4. A mechanism for the water chemistry effects was proposed that involved the corrosion characteristics of the entire loop system. While the model is speculative, most of the experimental observations are at least qualitatively consistent.

5. The possible differences in the water chemistry sensitivities for heavy water coolant operation were examined. For "cation control" of film growth rates, there is an equivalence of $\mathrm{pH}$ and $\mathrm{pD}$. For "anion control," the equivalent $\mathrm{pD}$ is almost a full unit higher than the designated $\mathrm{pH}$. Thus additional information will be required prior to applying the present data directly to the case of a heavy water coolant. 



\section{REFERENCES}

1. J. C. Griess et al., Effect of Heat Flux on the Corrosion of Aluminum by Water: Part III, Final Report on Tests Relative to the High-Flux Isotope Reactor, ORNL-3230, Union Carbide Corp., Oak Ridge Natl. Lab., December 1961.

2. J. C. Griess, H. C. Savage, and J. L. English, Effect of Heat Flux on the Corrosion of Aluminum by Water: Part IV, Tests Relative to the Advanced Test Reactor and Correlation with Previous Results, ORNL-3541, Union Carbide Corp., Oak Ridge Natl. Lab., February 1964.

3. A. E. Richt, R. W. Knight, and G. M. Adamson, Jr., Postirradiation Examination and Evaluation of the Performance of HFIR Fuel Elements, ORNL-4714, Union Carbide Corp., Oak Ridge Natl. Lab., December 1971.

4. V. A. Walker, M. J. Graber, and G. W. Gibson, ATR Fuel Materials Development Irradiation Results, Part II, IDO-17157, Phillips Petroleum Co. for the USAEC Idaho Operations Office, NRTS, Idaho Falls, Idaho, June 1966.

5. M. J. Graber et al., Performance Evaluation of Core II and III Advanced Test Reactor Fuel Elements, ANCR-1027, Aerojet Nuclear Co. for the USAEC Idaho Operations Office, NRTS, Idaho Falls, Idaho, October 1971.

6. M. L. Griebenow et al., "ATR Startup Fuel-Plate-Cladding Corrosion Test: Preliminary Data and Conclusions,” Trans. Am. Nuc. Soc. 14, 761 (1971).

7. G. H. Hanson et al., "ATR-ETR Rates of Oxide Film Formation on Aluminum Fuel Plates," Trans. Am. Nuc. Soc. 18, 127 (1974).

8. M. L. Griebenow and G. H. Hanson, ATR Core-I Thermal-Hydraulics Test Results, TR-727, EG\&G Idaho, Inc., Idaho National Engineering Laboratory, Idaho Falls, Idaho, September 1976.

9. M. L. Griebenow, G. H. Hanson, and A. P. Larrick, TRA Oxide Film Control and Surveillance (A Reference Document), RE-A-77-059 (TID-28272), EG\&G Idaho, Inc., Idaho National Engineering Laboratory, Idaho Falls, Idaho, October 1977.

10. R. S. Ondrejcin, Corrosion of 8001 Aluminum Fuel Cladding, DPST-72-371, Savannah River Laboratory, Aiken, S.C., May 1972.

11. R. S. Ondrejcin, Evaluation of Mark 22 Cladding, DPST-83-324, Savannah River Laboratory, Aiken, S.C., March 1983.

12. R. E. Pawel, D. K. Felde, and M. T. McFee, "The Development of an Improved Correlation for Corrosion Product Growth on Aluminum Alloy Fuel Cladding for the Advanced Neutron Source," 6th International Symposium on Environmental Degradation of Materials in Nuclear Power Systems, ed. R. E. Gold and E. P. Simonen, Minerals, Metals, and Materials Society, Warrendale, Pa., 1993, p. 467. 
13. B. H. Montgomery, R. E. Pawel, and G. L. Yoder, "The Advanced Neutron Source Test Loop Facility," Trans. Am. Nuc. Soc. 57, 300 (1988).

14. R. E. Pawel et al., "Fuel Cladding Corrosion Studies for the Advanced Neutron Source," Trans. Am. Nuc. Soc. 61, 388 (1990).

15. R. E. Pawel et al., "The Corrosion of 6061 Aluminum Under Heat Transfer Conditions in the ANS Corrosion Test Loop," Oxid. Metals 36 (1/2), 175 (1991).

16. R. E. Pawel et al., "The Corrosion of Behavior of 8001 Al Under Heat Transfer Conditions in an Aqueous Loop System," ORNL NPR-92/65, Martin Marietta Energy Systems, Inc., Oak Ridge Natl. Lab., April 1993.

17. D. L. Selby et al., Monthly Progress Report for the Advanced Neutron Source (ANS) Project, ORNL/ANS/INT-5V1 to -5V90, Martin Marietta Energy Systems, Inc., Oak Ridge Natl. Lab., 1988-95.

18. D. L. Selby, R. M. Harrington, and F. J. Peretz, Advanced Neutron Source (ANS) Project Progress Report, ORNL/TM-10579 (November 1987), ORNL/TM-10860 (February 1989), ORNL-6574 (April 1990), ORNL-6656 (February 1991), ORNL-6696 (February 1992), ORNL-6723 (January 1993), ORNL-6763 (January 1994), and ORNL-6821 (January 1995), Martin Marietta Energy Systems, Inc., Oak Ridge Natl. Lab.

19. R. E. Pawel, On the Kinetics of the Aluminum-Water Reaction During Exposure in High-Heat Flux Test Loops: A Computer Program for Oxidation Calculations, ORNL/TM-10602, Martin Marietta Energy Systems, Inc., Oak Ridge Natl. Lab., January 1988.

20. R. E. Pawel and D. W. Yarbrough, Modeling Heat Generation and Flow in the Advanced Neutron Source Test Loop Specimen, ORNL/TM-10603, Martin Marietta Energy Systems, Inc., Oak Ridge Natl. Lab., January 1988.

21. G. H. Hanson et al., Report of the ANS Aluminum Cladding Corrosion Workshop, CONF-8811203, Martin Marietta Energy Systems, Inc., Oak Ridge Natl. Lab., February 1989.

22. R. E. Pawel et al., The Development of a Preliminary Correlation of Data on Oxide Growth on 6061 Aluminum Under ANS Thermal-Hydraulic Conditions, ORNL/TM-11517, Martin Marietta Energy Systems, Inc., Oak Ridge Natl. Lab., June 1990.

23. R. E. Pawel, et al., "Cladding Corrosion Studies Under Heat Transfer Conditions. for the Advanced Neutron Source," Proceedings of the TMS Symposium on Radiation Facilities and Defect Studies, ed. C. L. Snead, BNL-47763, Brookhaven National Laboratory, Upton, N.Y., June 1992.

24. R. E. Pawel and S. J. Pawel, Summary of ANS Corrosion Loop Test Results for the Institut LaueLangevin Cladding Material, ORNL/M-4075, Martin Marietta Energy Systems, Inc., Oak Ridge Natl. Lab., February 1995. 
25. G. L. Yoder et al., "The Effect of Aluminum Corrosion on the Thermal-Hydraulic Design of the Advanced Neutron Source Reactor," Nucl. Eng. Des. 136, 401 (1992).

26. R. E. Pawel, et al., "The Corrosion Behavior of 8001 Al Under Heat Transfer Conditions in an Aqueous Loop System," Paper 188 in NACE CORROSION '93, National Association of Corrosion Engineers, New Orleans, March 1993.

27. B. S. Petukhov, "Heat Transfer and Friction in Turbulent Pipe Flow with Variable Physical Properties," Advanc. Heat Transfer 6, 504 (1970).

28. F. H. Sweeton and C. F. Baes, Jr., "The Solubility of Magnetite and Hydrolysis of Ferrous Ion in Aqueous Solution at Elevated Temperatures," J. Chem. Thermodyn. 2, 479 (1970).

29. C. F. Baes, Jr., and R. E. Mesmer, The Hydrolysis of Cations, John Wiley and Sons, New York, 1976.

30. D. W. Shoesmith and W. Lee, "The Ionization Constant of Heavy Water $\left(D_{2} O\right)$ in the Temperature Range 298 to $523 \mathrm{~K}$," Can. J. Chem. 54, 3553 (1976).

31. R. E. Mesmer and D. L. Herting, "Thermodynamics of Ionization of $\mathrm{D}_{2} \mathrm{O}$ and $\mathrm{D}_{2} \mathrm{PO}_{4}$," J. Solution Chem. 7, 901 (1978).

32. P. Salomaa, L. L. Schaleger, and F. A. Long, "Solvent Deuterium Isotope Effects on Acid-Base Equilibria," J. Amer. Chem. Soc. 86, 1 (1964). 

Appendix A. EFFECTIVE TEST PARAMETERS FOR ANS CTESTS 

Key to terminology in Table A.1

\begin{tabular}{ll}
\hline \multicolumn{1}{c}{ Parameter } & \multicolumn{1}{c}{ Interpretation } \\
\hline Al alloy material & Specific dilute alloy used as specimen material \\
Test initiated & Date on which startup was achieved \\
$\mathrm{pH}$ & Average coolant $\mathrm{pH}$, measured at $25^{\circ} \mathrm{C}$ in bypass loop \\
$\mathrm{L}, \mu \mathrm{S} / \mathrm{m}$ & Average coolant conductivity, measured as above \\
$\mathrm{V}_{\mathrm{c}}, \mathrm{m} / \mathrm{s}$ & Coolant velocity, calculated from mass flow \\
$\mathrm{T}_{\mathrm{ci}},{ }^{\circ} \mathrm{C}$ & Coolant inlet temperature, probe at specimen inlet \\
$\mathrm{P}, \mathrm{kW}$ & Total power dissipated in specimen \\
$\phi_{\mathrm{avg}}, \mathrm{MW} / \mathrm{m}^{2}$ & Average heat flux across main reaction areas \\
Duration, $\mathrm{h}$ & Total length of test \\
Local $\mathrm{T}_{\mathrm{c}},{ }^{\circ} \mathrm{C}$ & Local bulk coolant temperature at specified specimen positions \\
Local $\mathrm{T}_{\mathrm{x} / \mathrm{c}},{ }^{\circ} \mathrm{C}$ & Local interface temperature at specified specimen positions \\
Local $\phi, \mathrm{MW} / \mathrm{m}^{2}$ & Local heat flux at specified specimen positions \\
Rate con $(\mathrm{k}), \mu \mathrm{m}^{1.351} / \mathrm{h}$ & Local rate constant for film growth at specified specimen positions \\
EOT film thk, $\mu \mathrm{m}$ & End-of-test measured film thickness at specified specimen positions \\
sp; c & Spalled or partially spalled; isolated craters \\
$\Rightarrow ; \Leftarrow$ & Arrows signify "continuing" or "approaching"; read left or right \\
$\mathrm{NA}$ & Not available \\
\hline
\end{tabular}


A- 4

Table A.1. Effective test parameters for ANS CTESTs 3-50

\begin{tabular}{|c|c|c|c|c|c|c|c|}
\hline Parameter & CT-3 & CT-4 & CT-5 & CT-6 & CT-7A & CT-7B & CT-7C \\
\hline Al alloy material & 6061 & 6061 & 6061 & 6061 & 6061 & $\Leftarrow$ & $\Leftarrow$ \\
\hline Test initiated & $6 / 88$ & $8 / 88$ & $9 / 88$ & $12 / 88$ & $1 / 89$ & $\Leftarrow$ & $\Leftarrow$ \\
\hline $\mathrm{pH}$ & 5.9 & 5.0 & 5.0 & 4.5 & 5.0 & 4.5 & 5.0 \\
\hline$L, \mu S / m$ & 135 & 405 & 465 & 1300 & 540 & 1400 & 500 \\
\hline$V_{c}, m / s$ & 27.1 & 27.7 & 12.8 & 24.2 & 27.5 & $\Leftarrow$ & $\Leftarrow$ \\
\hline $\mathrm{T}_{\mathrm{ci}}{ }^{\circ} \mathrm{C}$ & 80 & 79 & 75 & 80 & 80 & $\Leftarrow$ & $\Leftarrow$ \\
\hline$P, \mathbf{k W}$ & 41.6 & 41.2 & 19.0 & 41.6 & 41.6 & $\Leftarrow$ & $\Leftarrow$ \\
\hline$\phi_{\mathrm{vvg}}, \mathrm{MW} / \mathrm{m}^{2}$ & 11.6 & 11.5 & 5.3 & 11.6 & 11.6 & $\Leftarrow$ & $\Leftarrow$ \\
\hline Duration, $\mathbf{h}$ & 70 & 116 & 340 & 220 & 60 & $\Rightarrow 320$ & $\Rightarrow 410$ \\
\hline \multicolumn{8}{|l|}{ Local $\mathrm{T}_{c},{ }^{\circ} \mathrm{C}$} \\
\hline Position 2 & 83 & 83 & 79 & 84 & 83 & $\Leftarrow$ & $\Leftarrow$ \\
\hline Position 4 & 90 & 90 & 85 & 93 & 91 & $\Leftarrow$ & $\Leftarrow$ \\
\hline Position 6 & 96 & 97 & 92 & 101 & 99 & $\Leftarrow$ & $\Leftarrow$ \\
\hline \multicolumn{8}{|l|}{ Local $\mathrm{T}_{x / c},{ }^{\circ} \mathrm{C}$} \\
\hline Position 2 & 147 & 146 & 136 & 156 & 148 & $\Leftarrow$ & $\Leftarrow$ \\
\hline Position 4 & 155 & 154 & 143 & 164 & 156 & $\Leftarrow$ & $\Leftarrow$ \\
\hline Position 6 & 163 & 163 & 150 & 173 & 165 & $\Leftarrow$ & $\Leftarrow$ \\
\hline \multicolumn{8}{|l|}{ Local $\phi, M W / \mathrm{m}^{2}$} \\
\hline Position 2 & 11.3 & 11.0 & 5.2 & 11.4 & 11.2 & $\Leftarrow$ & $\Leftarrow$ \\
\hline Position 4 & 11.6 & 11.5 & 5.3 & 11.6 & 11.6 & $\Leftarrow$ & $\Leftrightarrow$ \\
\hline Position 6 & 12.0 & 12.5 & 5.5 & 12.0 & 12.1 & $\Leftarrow$ & $\Leftarrow$ \\
\hline \multicolumn{8}{|c|}{ Rate con $(\mathrm{k}), \mu \mathrm{m}^{1.351} / \mathrm{h}$} \\
\hline Position 2 & 0.688 & 0.389 & 0.0844 & 0.0248 & 0.262 & 0.0287 & 0.0607 \\
\hline Position 4 & 0.955 & 0.597 & 0.131 & 0.0384 & 0.370 & 0.0418 & 0.0632 \\
\hline Position 6 & 1.259 & 0.991 & 0.187 & 0.0657 & 0.522 & 0.0727 & 0.0979 \\
\hline \multicolumn{8}{|l|}{ EOT film thk, $\mu \mathrm{m}$} \\
\hline Position 2 & 20.5 & 18.5 & 10.6 & 5.2 & $\Rightarrow$ & $\Rightarrow$ & 16.9 \\
\hline Position 4 & sp & sp & 15.0 & 10.5 & $\Rightarrow$ & $\Rightarrow$ & 20.1 \\
\hline Position 6 & sp & sp & 19.9 & 10.8 & $\Rightarrow$ & $\Rightarrow$ & sp \\
\hline
\end{tabular}




\section{A-5}

Table A.1 (continued)

\begin{tabular}{|c|c|c|c|c|c|c|c|}
\hline Parameter & CT-8 & CT-9 & CT-10 & CT-11 & CT-12 & CT-13 & CT-14 \\
\hline $\mathrm{Al}$ alloy material & 6061 & 6061 & 6061 & 6061 & 6061 & 6061 & 6061 \\
\hline Test initiated & $3 / 89$ & $3 / 89$ & $4 / 89$ & $5 / 89$ & $6 / 89$ & $7 / 89$ & $8 / 89$ \\
\hline $\mathrm{pH}$ & 5.0 & 5.0 & 5.0 & 5.0 & 6.0 & 5.0 & 5.0 \\
\hline$L, \mu \mathrm{S} / \mathrm{m}$ & 530 & 490 & 510 & 520 & 160 & 615 & 465 \\
\hline $\mathrm{V}_{\mathrm{c}}, \mathrm{m} / \mathrm{s}$ & 25.4 & 25.5 & 25.5 & 19.2 & 28.0 & 27.8 & 25.6 \\
\hline $\mathrm{T}_{\mathrm{cj}},{ }^{\circ} \mathrm{C}$ & 43 & 57 & 39 & 39 & 80 & 67 & 49 \\
\hline $\mathrm{P}, \mathrm{kW}$ & 42.0 & 43.4 & 55.6 & 42.7 & 42.3 & 38.0 & 22.2 \\
\hline$\phi_{\mathrm{avg}}, \mathrm{MW} / \mathrm{m}^{2}$ & 11.7 & 11.5 & 15.5 & 11.9 & 11.8 & 10.6 & 6.2 \\
\hline Duration, $\mathrm{h}$ & 330 & 240 & 280 & 360 & 52 & 340 & 460 \\
\hline \multicolumn{8}{|l|}{ Local $\mathrm{T}_{\mathrm{c}},{ }^{\circ} \mathrm{C}$} \\
\hline Position 2 & 47 & 61 & 45 & 44 & 84 & 71 & 51 \\
\hline Position 4 & 56 & 70 & 56 & 55 & 92 & 78 & 56 \\
\hline Position 6 & 64 & 78 & 67 & 66 & 99 & 84 & 61 \\
\hline \multicolumn{8}{|l|}{ Local $\mathrm{T}_{\mathrm{x} c},{ }^{\circ} \mathrm{C}$} \\
\hline Position 2 & 127 & 136 & 146 & 147 & 148 & 131 & 95 \\
\hline Position 4 & 135 & 146 & 158 & 155 & 156 & 139 & 99 \\
\hline Position 6 & 143 & 156 & 175 & 164 & 166 & 147 & 103 \\
\hline \multicolumn{8}{|l|}{ Local $\phi, \mathrm{MW} / \mathrm{m}^{2}$} \\
\hline Position 2 & 11.3 & 11.4 & 14.5 & 11.6 & 11.4 & 10.1 & 6.2 \\
\hline Position 4 & 11.7 & 12.1 & 15.5 & 11.9 & 11.8 & 10.6 & 6.2 \\
\hline Position 6 & 12.1 & 12.7 & 17.2 & 12.3 & 12.4 & 11.1 & 6.2 \\
\hline \multicolumn{8}{|c|}{ Rate con $(\mathbf{k}), \mu \mathrm{m}^{1.351} / \mathrm{h}$} \\
\hline Position 2 & 0.0154 & 0.0955 & 0.0391 & 0.0159 & 0.992 & 0.0977 & 0.005 \\
\hline Position 4 & 0.0196 & 0.181 & 0.0918 & 0.0304 & 1.266 & 0.142 & 0.005 \\
\hline Position 6 & 0.0349 & 0.287 & 0.192 & 0.0620 & 1.636 & 0.181 & 0.005 \\
\hline \multicolumn{8}{|l|}{ EOT film thk, $\mu \mathrm{m}$} \\
\hline Position 2 & 7.6 & 10.9 & 7.4 & 4.5 & 20.8 & 18.6 & 4.1 \\
\hline Position 4 & 7.6 & 21.7 & 15.4 & 7.5 & $\mathbf{s p}$ & 22.0 & 4.2 \\
\hline Position 6 & 9.8 & $\mathbf{s p}$ & sp & 12.6 & sp & 28.2 & 4.4 \\
\hline
\end{tabular}


Table A.1 (continued)

\begin{tabular}{|c|c|c|c|c|c|c|c|}
\hline Parameter & CT-15 & CT-16 & CT-17 & CT-18 & CT-19 & CT -20 & CT-21 \\
\hline Al alloy material & 6061 & 6061 & 6061 & 6061 & 6061 & 6061 & 6061 \\
\hline Test initiated & $9 / 89$ & $10 / 89$ & $11 / 89$ & $12 / 89$ & $1 / 90$ & $3 / 90$ & $4 / 90$ \\
\hline $\mathrm{pH}$ & 5.0 & 5.0 & 5.0 & 5.4 & $4.9 / 5.0$ & 5.0 & 5.1 \\
\hline$L, \mu S / m$ & 550 & 540 & 500 & 325 & $500 / 430$ & 450 & 370 \\
\hline $\mathrm{V}_{c}, \mathrm{~m} / \mathrm{s}$ & 25.6 & 25.6 & 25.5 & 10.0 & 20.1 & 15.1 & 25.6 \\
\hline $\mathrm{T}_{\mathrm{ci},}{ }^{\circ} \mathrm{C}$ & 49 & 49 & 49 & 49 & 49 & 49 & 49 \\
\hline $\mathrm{P}, \mathrm{kW}$ & 44.8 & 67.0 & 21.8 & 22.6 & 45.0 & 45.0 & 44.7 \\
\hline$\phi_{\mathrm{evg}}, \mathrm{MW} / \mathrm{m}^{2}$ & 12.5 & 18.7 & 6.1 & 6.3 & 12.0 & 12.6 & 12.4 \\
\hline Duration, $\mathrm{h}$ & 570 & 58 & 380 & 504 & 504 & 119 & 497 \\
\hline \multicolumn{8}{|l|}{ Local $\mathrm{T}_{c},{ }^{\circ} \mathrm{C}$} \\
\hline Position 2 & 53 & 56 & 51 & 55 & 55 & 57 & 53 \\
\hline Position 4 & 62 & 69 & 56 & 66 & 66 & 72 & 62 \\
\hline Position 6 & 71 & 82 & 60 & 77 & 77 & 87 & 71 \\
\hline \multicolumn{8}{|l|}{ Local $\mathrm{T}_{x \mathrm{xc}},{ }^{\circ} \mathrm{C}$} \\
\hline Position 2 & 136 & 169 & 94 & 145 & 152 & 180 & 134 \\
\hline Position 4 & 144 & 181 & 100 & 154 & 162 & 192 & 142 \\
\hline Position 6 & 152 & 201 & 104 & 164 & 176 & 208 & 153 \\
\hline \multicolumn{8}{|l|}{ Local $\phi, M W / m^{2}$} \\
\hline Position 2 & 12.3 & 17.3 & 6.1 & 6.2 & 12.1 & 12.3 & 11.9 \\
\hline Position 4 & 12.6 & 18.2 & 6.1 & 6.3 & 12.5 & 12.7 & 12.3 \\
\hline Position 6 & 12.8 & 20.2 & 6.1 & 6.5 & 13.4 & 13.5 & 13.2 \\
\hline \multicolumn{8}{|c|}{ Rate con $(\mathrm{k}), \mu \mathrm{m}^{1.351} / \mathrm{h}$} \\
\hline Position 2 & 0.0126 & 0.166 & 0.004 & 0.0907 & 0.0381 & 0.249 & 0.0407 \\
\hline Position 4 & 0.0193 & 0.246 & 0.004 & 0.125 & 0.0637 & 0.337 & 0.0563 \\
\hline Position 6 & 0.0280 & 0.608 & 0.004 & 0.181 & 0.118 & 0.601 & 0.103 \\
\hline \multicolumn{8}{|l|}{ EOT film thk, $\mu \mathrm{m}$} \\
\hline Position 2 & 6.0 & 7.5 & 3.5 & 20.0 & 7.2 & 11.9 & 8.9 \\
\hline Position 4 & 6.8 & 10.9 & 3.8 & 23.0 & 14.7 & 17.2 & 11.9 \\
\hline Position 6 & 8.6 & sp & 4.5 & 31.6 & sp & sp & 24.0 \\
\hline
\end{tabular}




\section{A-7}

Table A.1 (continued)

\begin{tabular}{|c|c|c|c|c|c|c|c|}
\hline Parameter & CT-22A & CT-22B & CT-23 & CT-24 & CT-25 & CT-26 & CT-27 \\
\hline $\mathrm{Al}$ alloy material & 6061 & $\Leftarrow$ & 6061 & 6061 & 6061 & 6061 & 6061 \\
\hline Test initiated & $6 / 90$ & $7 / 90$ & $10 / 90$ & $1 / 91$ & $2 / 91$ & $5 / 91$ & $6 / 91$ \\
\hline $\mathrm{pH}$ & 5.1 & 5.0 & 5.0 & $5(?)$ & $5(?)$ & 4.5 & 5.0 \\
\hline $\mathrm{L}, \mu \mathrm{S} / \mathrm{m}$ & 380 & 450 & 420 & 280 & 285 & 1800 & 550 \\
\hline $\mathrm{V}_{c}, \mathrm{~m} / \mathrm{s}$ & 25.7 & $\Leftarrow$ & 9.0 & 35.6 & 22.3 & 25.6 & 25.6 \\
\hline $\mathrm{T}_{\mathrm{ei}},{ }^{\circ} \mathrm{C}$ & 49 & $\Leftarrow$ & 49 & 49 & 49 & 49 & 49 \\
\hline $\mathrm{P}, \mathrm{kW}$ & 22.2 & 44.6 & 20.5 & 52.6 & 43.2 & 44.5 & 45.0 \\
\hline$\phi_{\mathrm{avg}}, \mathrm{MW} / \mathrm{m}^{2}$ & 6.2 & 12.4 & 5.7 & 14.7 & 12.1 & 12.4 & 12.6 \\
\hline Duration, $\mathrm{h}$ & 477 & $\Rightarrow 822$ & 505 & 383 & 160 & 480 & 504 \\
\hline \multicolumn{8}{|l|}{ Local $\mathrm{T}_{c},{ }^{\circ} \mathrm{C}$} \\
\hline Position 2 & 51 & 54 & 55 & 53 & 54 & 53 & 53 \\
\hline Position 4 & 56 & 62 & 66 & 60 & 63 & 62 & 62 \\
\hline Position 6 & 60 & 70 & 77 & 68 & 73 & 70 & 70 \\
\hline \multicolumn{8}{|l|}{ Local $\mathrm{T}_{\mathbf{x} / c},{ }^{\circ} \mathrm{C}$} \\
\hline Position 2 & 95 & 136 & 144 & 126 & 142 & 137 & 135 \\
\hline Position 4 & 99 & 142 & 152 & 134 & 149 & 143 & 142 \\
\hline Position 6 & 102 & 149 & 162 & 142 & 160 & 149 & 152 \\
\hline \multicolumn{8}{|l|}{ Local $\phi, M W / \mathrm{m}^{2}$} \\
\hline Position 2 & 6.2 & 12.3 & 5.6 & 14.0 & 11.7 & 12.3 & 12.1 \\
\hline Position 4 & 6.2 & 12.4 & 5.7 & 14.7 & 11.9 & 12.4 & 12.5 \\
\hline Position 6 & 6.2 & 12.6 & 5.9 & 15.3 & 12.6 & 12.5 & 13.2 \\
\hline \multicolumn{8}{|c|}{ Rate con $(k), \mu m^{1.351} / \mathrm{h}$} \\
\hline Position 2 & 0.012 & 0.0327 & 0.0237 & 0.0614 & 0.207 & 0.0025 & 0.028 \\
\hline Position 4 & 0.014 & 0.0297 & 0.0381 & 0.0871 & 0.242 & 0.0024 & 0.034 \\
\hline Position 6 & 0.017 & 0.0418 & 0.0597 & 0.123 & 0.358 & 0.0039 & 0.054 \\
\hline \multicolumn{8}{|l|}{ EOT film thk, $\mu \mathrm{m}$} \\
\hline Position 2 & $\Rightarrow$ & 8.9 & 8.5 & 10.9 & 14.1 & 3.4 & 9.2 \\
\hline Position 4 & $\Rightarrow$ & 11.9 & 11.1 & 15.1 & 14.3 & 3.0 & 9.89 \\
\hline Position 6 & $\Rightarrow$ & 24.0 & 16.0 & sp & 23.5 & 4.2 & 14.4 \\
\hline
\end{tabular}


Table A.1 (continued)

\begin{tabular}{|c|c|c|c|c|c|c|c|}
\hline Parameter & CT-28 & CT-29 & CT-30 & CT-31 & CT-32 & CT-33 & CT-34 \\
\hline $\mathrm{Al}$ alloy material & 6061 & 8001 & 8001 & 8001 & 8001 & 8081 & 6061 \\
\hline Test initiated & $7 / 91$ & $8 / 91$ & $11 / 91$ & $2 / 92$ & $4 / 92$ & $7 / 92$ & $4 / 93$ \\
\hline $\mathrm{pH}$ & 5.0 & 5.0 & 5.4 & 5.0 & 6.0 & 5.4 & 5.1 \\
\hline$L, \mu S / m$ & 450 & 400 & 160 & 370 & 50 & 180 & 380 \\
\hline $\mathrm{V}_{\mathrm{c}}, \mathrm{m} / \mathrm{s}$ & 23.6 & 6.1 & 7.6 & 3.0 & 3.0 & 7.2 & 25.8 \\
\hline $\mathrm{T}_{\mathrm{ci}},{ }^{\circ} \mathrm{C}$ & 49 & 49 & 49 & 50 & 65 & 65 & 49 \\
\hline $\mathrm{P}, \mathrm{kW}$ & 52.5 & 16.2 & 13.7 & 8.25 & 3.63 & 16.1 & 45.0 \\
\hline$\phi_{\mathrm{avz}}, \mathrm{MW} / \mathrm{m}^{2}$ & 14.7 & 4.5 & 3.8 & 2.3 & 1.0 & 4.5 & 12.5 \\
\hline Duration, $h$ & 143 & 1225 & 1293 & 1220 & 1344 & 740 & 334 \\
\hline \multicolumn{8}{|l|}{ Local $\mathrm{T}_{\mathrm{e}},{ }^{\circ} \mathrm{C}$} \\
\hline Position 2 & 55 & 56 & 53 & 55 & 68 & 71 & 54 \\
\hline Position 4 & 66 & 69 & 62 & 68 & 73 & 81 & 62 \\
\hline Position 6 & 77 & 82 & 70 & 80 & 78 & 92 & 70 \\
\hline \multicolumn{8}{|l|}{ Local $\mathrm{T}_{\mathrm{x} / \mathrm{c}},{ }^{\circ} \mathrm{C}$} \\
\hline Position 2 & 154 & 152 & 123 & 144 & 106 & 148 & 133 \\
\hline Position 4 & 164 & 161 & 130 & 152 & 111 & 158 & 142 \\
\hline Position 6 & 176 & 172 & 138 & 163 & 116 & 172 & 154 \\
\hline \multicolumn{8}{|l|}{ Local $\phi, M W / m^{2}$} \\
\hline Position 2 & 14.0 & 4.4 & 3.7 & 2.3 & 1.0 & 4.3 & 11.8 \\
\hline Position 4 & 14.6 & 4.5 & 3.8 & 2.3 & 1.0 & 4.5 & 12.4 \\
\hline Position 6 & 15.4 & 4.6 & 3.9 & 2.4 & 1.0 & 4.8 & 13.5 \\
\hline \multicolumn{8}{|c|}{ Rate con $(\mathrm{k}), \mu \mathrm{m}^{1.351} / \mathrm{h}$} \\
\hline Position 2 & 0.065 & 0.0327 & 0.0246 & 0.0128 & 0.0165 & 0.0899 & 0.0554 \\
\hline Position 4 & 0.105 & 0.0447 & 0.0396 & 0.0160 & 0.0262 & 0.1824 & 0.104 \\
\hline Position 6 & 0.183 & 0.0537 & 0.0583 & 0.0263 & 0.0363 & 0.2907 & 0.183 \\
\hline \multicolumn{8}{|l|}{ EOT film thk, $\mu \mathrm{m}$} \\
\hline Position 2 & 12.1 & 13.8 & 15.9 & 8.8 & 11.8 & 24.0 & 12.3 \\
\hline Position 4 & 16.7 & 14.5 & 21.6 & 10.6 & 16.2 & 35.0 & 17.4 \\
\hline Position 6 & sp & 14.5 & 28.6 & 15.1 & 21.4 & 60.4 & $24.1 \mathrm{sp}$ \\
\hline
\end{tabular}




\section{A-9}

Table A.1 (continued)

\begin{tabular}{|c|c|c|c|c|c|c|c|}
\hline Parameter & CT-35 & CT-36 & CT-37 & CT-38A & CT-38B & СТ-39 & CT -40 \\
\hline $\mathrm{Al}$ alloy material & 6061 & pure Al & 8001 & 1100 & $\Leftarrow$ & pure $\mathrm{Al}$ & 6061 \\
\hline Test initiated & $5 / 93$ & $7 / 93$ & $11 / 93$ & $12 / 93$ & $1 / 94$ & $2 / 94$ & $3 / 94$ \\
\hline $\mathrm{pH}$ & 5.0 & 4.9 & 5.0 & 4.9 & 5.0 & 4.9 & 5.0 \\
\hline$L, \mu S / m$ & 480 & 470 & 520 & 600 & 540 & 620 & 520 \\
\hline $\mathrm{V}_{\mathrm{c}}, \mathrm{m} / \mathrm{s}$ & 25.6 & 25.6 & 25.6 & 25.6 & $\Leftarrow$ & 25.4 & 25.7 \\
\hline $\mathrm{T}_{\mathrm{ei}},{ }^{\circ} \mathrm{C}$ & 49 & 49 & 49 & 49 & $\Leftarrow$ & 49 & 49 \\
\hline $\mathrm{P}, \mathrm{kW}$ & 42.7 & 43.0 & 45.1 & 43.0 & 50.1 & 42.7 & 45.1 \\
\hline$\phi_{\text {avg }}, M W / m^{2}$ & 11.9 & 12.0 & 12.6 & 12.0 & 14.0 & 11.9 & 12.6 \\
\hline Duration, $\mathrm{h}$ & 640 & 554 & 523 & 502 & $\Rightarrow 710$ & 711 & 550 \\
\hline \multicolumn{8}{|l|}{ Local $\mathrm{T}_{c},{ }^{\circ} \mathrm{C}$} \\
\hline Position 2 & 53 & 53 & 53 & 53 & 54 & 53 & 53 \\
\hline Position 4 & 61 & 61 & 62 & 61 & 63 & 61 & 61 \\
\hline Position 6 & 69 & 69 & 70 & 69 & 72 & 69 & 70 \\
\hline \multicolumn{8}{|l|}{ Local $\mathrm{T}_{x / c},{ }^{\circ} \mathrm{C}$} \\
\hline Position 2 & 130 & 131 & 134 & 133 & 146 & 133 & 136 \\
\hline Position 4 & 138 & 139 & 142 & 139 & 153 & 139 & 143 \\
\hline Position 6 & 149 & 149 & 155 & 146 & 161 & 146 & 151 \\
\hline \multicolumn{8}{|l|}{ Local $\phi, M W / \mathrm{m}^{2}$} \\
\hline Position 2 & 11.3 & 11.5 & 11.9 & 11.8 & 13.7 & 11.8 & 12.2 \\
\hline Position 4 & 11.8 & 11.8 & 12.3 & 11.9 & 13.9 & 11.9 & 12.5 \\
\hline Position 6 & 12.6 & 12.6 & 13.5 & 12.2 & 14.3 & 12.1 & 13.0 \\
\hline \multicolumn{8}{|c|}{ Rate con $(\mathrm{k}), \mu \mathrm{m}^{1.351} / \mathrm{h}$} \\
\hline Position 2 & $\Rightarrow .0193$ & 0.0184 & 0.0323 & 0.0026 & 0.0016 & 0.0029 & 0.0096 \\
\hline Position 4 & $\Rightarrow .0283$ & 0.0270 & 0.0514 & 0.0032 & 0.0024 & 0.0032 & 0.0124 \\
\hline Position 6 & $\Rightarrow .0594$ & 0.0619 & 0.116 & 0.0042 & 0.0054 & 0.0041 & 0.0280 \\
\hline \multicolumn{8}{|l|}{ EOT film thk, $\mu \mathrm{m}$} \\
\hline Position 2 & 11.2 & 7.4 & 10.8 & $\Rightarrow$ & 3.8 & 3.8 & 5.9 \\
\hline Position 4 & 15.1 & 11.8 & 15.3 & $\Rightarrow$ & 4.2 & 4.3 & 7.6 \\
\hline Position 6 & 22.4 & $16.2 \mathrm{sp}$ & 28.1 & $\Rightarrow$ & 5.0 & 5.1 & 10.8 \\
\hline
\end{tabular}


Table A.1 (continued)

\begin{tabular}{|c|c|c|c|c|c|c|c|}
\hline Parameter & CT-41A & CT-41B & CT- $42 \mathrm{~A}$ & CT- $42 \mathrm{~B}$ & CT- $43 \mathrm{~A}$ & CT-43B & CT- 44 \\
\hline Al alloy material & 6061 & $\Leftarrow$ & 8001 & $\Leftarrow$ & $\pi L$ & $\Leftarrow$ & 6061 \\
\hline Test initiated & $4 / 94$ & $4 / 94$ & $6 / 94$ & $7 / 94$ & $8 / 94$ & $9 / 94$ & $11 / 94$ \\
\hline pH & 5.05 & 4.8 & 5.0 & $\Leftarrow$ & 5.0 & $\Leftarrow$ & 4.7 \\
\hline$L, \mu S / m$ & 450 & 700 & 500 & 480 & 510 & 520 & 1160 \\
\hline$V_{c}, \mathrm{~m} / \mathrm{s}$ & 25.6 & $\Leftarrow$ & 25.6 & $\Leftarrow$ & 25.6 & $\Leftarrow$ & 25.6 \\
\hline $\mathrm{T}_{c i},{ }^{\circ} \mathrm{C}$ & 49 & $\Leftarrow$ & 50 & 52 & 49 & 50 & 48 \\
\hline $\mathrm{P}, \mathrm{kW}$ & 54.5 & $\Leftarrow$ & 45.2 & 50.6 & 45.2 & 50.4 & 44.8 \\
\hline$\phi_{\mathrm{avg}}, \mathrm{MW} / \mathrm{m}^{2}$ & 15.3 & $\Leftarrow$ & 12.6 & 14.1 & 12.6 & 14.0 & 12.5 \\
\hline Duration, $\mathrm{h}$ & 56 & $\Rightarrow 157$ & 660 & $\Rightarrow 974$ & 384 & $\Rightarrow 669$ & 389 \\
\hline \multicolumn{8}{|l|}{ Local $\mathrm{T}_{c},{ }^{\circ} \mathrm{C}$} \\
\hline Position 2 & 54 & $\Leftarrow$ & 54 & 57 & 54 & 55 & 52 \\
\hline Position 4 & 65 & $\Leftarrow$ & 62 & 66 & 62 & 64 & 60 \\
\hline Position 6 & 75 & $\Leftarrow$ & 71 & 76 & 70 & 73 & 68 \\
\hline \multicolumn{8}{|l|}{ Local $\mathrm{T}_{\mathrm{x} / \mathrm{e}},{ }^{\circ} \mathrm{C}$} \\
\hline Position 2 & 148 & $\Leftarrow$ & 135 & 142 & 136 & 143 & 136 \\
\hline Position 4 & 161 & $\Leftarrow$ & 143 & 152 & 143 & 153 & 142 \\
\hline Position 6 & 176 & $\Leftarrow$ & 155 & 172 & 152 & 166 & 148 \\
\hline \multicolumn{8}{|l|}{ Local $\phi, M W / m^{2}$} \\
\hline Position 2 & 14.3 & $\Leftarrow$ & 12.0 & 11.8 & 12.2 & 13.2 & 12.4 \\
\hline Position 4 & 15.2 & $\Leftarrow$ & 12.4 & 11.9 & 12.5 & 13.9 & 12.5 \\
\hline Position 6 & 16.5 & $\Leftarrow$ & 13.5 & 12.2 & 13.1 & 15.1 & 12.6 \\
\hline \multicolumn{8}{|c|}{ Rate con $(k), \mu m^{1.351} / h$} \\
\hline Position 2 & 0.175 & 0.0335 & 0.0201 & 0.0196 & 0.0323 & 0.0381 & 0.002 \\
\hline Position 4 & 0.297 & 0.0581 & 0.0304 & 0.0336 & 0.0450 & 0.0525 & 0.002 \\
\hline Position 6 & 0.479 & 0.0932 & 0.0656 & 0.0909 & 0.0698 & 0.0819 & 0.002 \\
\hline \multicolumn{8}{|l|}{ EOT film thk, $\mu \mathrm{m}$} \\
\hline Position 2 & $\Rightarrow$ & 10.1 & $\Rightarrow$ & 12.9 & $\Rightarrow$ & 15.6 & 4.0 \\
\hline Position 4 & $\Rightarrow$ & 13.6 & $\Rightarrow$ & 18.4 & $\Rightarrow$ & 20.3 & 4.2 \\
\hline Position 6 & $\Rightarrow$ & $23.1 \mathrm{sp}$ & $\Rightarrow$ & $34.5 \mathrm{sp}$ & $\Rightarrow$ & $28.1 \mathrm{c}$ & 4.6 \\
\hline
\end{tabular}


A-11

Table A.1 (continued)

\begin{tabular}{|c|c|c|c|c|c|c|c|}
\hline Parameter & CT-45 & CT-46A & CT-46B & CT- $47 \mathrm{~A}$ & CT-47B & $\mathrm{CT}-47 \mathrm{C}$ & CT47D \\
\hline Al alloy material & 6061 & 6061 & $\Leftarrow$ & 6061 & $\Leftarrow$ & $\Leftarrow$ & $\Leftarrow$ \\
\hline Test initiated & $1 / 95$ & $3 / 95$ & $3 / 95$ & $5 / 95$ & $5 / 95$ & $5 / 95$ & $5 / 95$ \\
\hline $\mathrm{pH}$ & 4.65 & 4.65 & 5.05 & 5.05 & 5.28 & $\Leftarrow$ & 5.0 \\
\hline$L, \mu S / m$ & 1100 & 900 & 450 & 420 & 240 & $\Leftarrow$ & 500 \\
\hline$V_{c}, \mathrm{~m} / \mathrm{s}$ & 25.9 & 15.5 & $\Leftarrow$ & 15.5 & $\Leftarrow$ & 11.2 & $\Leftarrow$ \\
\hline $\mathrm{T}_{\mathrm{c} ;},{ }^{\circ} \mathrm{C}$ & 49 & 49 & $\Leftarrow$ & 49 & $\Leftarrow$ & $\Leftarrow$ & $\Leftarrow$ \\
\hline $\mathrm{P}, \mathrm{kW}$ & 54.0 & 22.3 & $\Leftarrow$ & 22.3 & $\Leftarrow$ & $\Leftarrow$ & $\Leftarrow$ \\
\hline$\phi_{\mathrm{avg}}, \mathrm{MW} / \mathrm{m}^{2}$ & 15.0 & 6.2 & $\Leftarrow$ & 6.2 & $\Leftarrow$ & $\Leftarrow$ & $\Leftarrow$ \\
\hline Duration, $\mathrm{h}$ & 290 & 760 & $\Rightarrow 920$ & 65 & $\Rightarrow 175$ & $\Rightarrow 280$ & $\Rightarrow 375$ \\
\hline \multicolumn{8}{|l|}{ Local $\mathrm{T}_{c},{ }^{\circ} \mathrm{C}$} \\
\hline Position 2 & 53 & 48 & $\Leftarrow$ & 51 & $\Leftarrow$ & 53 & $\Leftarrow$ \\
\hline Position 4 & 63 & 55 & $\Leftarrow$ & 58 & $\Leftarrow$ & 62 & $\Leftarrow$ \\
\hline Position 6 & 73 & 61 & $\Leftarrow$ & 65 & $\Leftarrow$ & 71 & $\Leftarrow$ \\
\hline \multicolumn{8}{|l|}{ Local $\mathrm{T}_{\mathrm{x} / \mathrm{e}},{ }^{\circ} \mathrm{C}$} \\
\hline Position 2 & 152 & 113 & $\Leftarrow$ & 116 & $\Leftarrow$ & 136 & $\Leftarrow$ \\
\hline Position 4 & 158 & 119 & $\Leftarrow$ & 121 & $\Leftarrow$ & 143 & $\Leftarrow$ \\
\hline Position 6 & 165 & 126 & $\Leftarrow$ & 126 & $\Leftarrow$ & 150 & $\Leftarrow$ \\
\hline \multicolumn{8}{|l|}{ Local $\phi, M W / m^{2}$} \\
\hline Position 2 & 14.96 & 6.0 & $\Leftarrow$ & 6.1 & $\Leftarrow$ & $\Leftarrow$ & $\Leftarrow$ \\
\hline Position 4 & 15.04 & 6.2 & $\Leftarrow$ & 6.2 & $\Leftarrow$ & $\Leftarrow$ & $\Leftarrow$ \\
\hline Position 6 & 15.18 & 6.4 & $\Leftarrow$ & 6.3 & $\Leftarrow$ & $\Leftarrow$ & $\Leftarrow$ \\
\hline \multicolumn{8}{|c|}{ Rate con $(k), \mu \mathrm{m}^{\mathrm{l} .351} / \mathrm{h}$} \\
\hline Position 2 & 0.003 & 0.006 & 0.006 & 0.023 & 0.023 & 0.063 & 0.019 \\
\hline Position 4 & 0.003 & 0.010 & 0.010 & 0.025 & 0.025 & 0.097 & 0.011 \\
\hline Position 6 & 0.003 & 0.009 & 0.009 & 0.023 & 0.023 & 0.101 & 0.013 \\
\hline \multicolumn{8}{|l|}{ EOT film thk, $\mu \mathrm{m}$} \\
\hline Position 2 & 4 & $\Rightarrow$ & 3.1 & $\Rightarrow$ & $\Rightarrow$ & $\Rightarrow$ & 5.6 \\
\hline Position 4 & 4 & $\Rightarrow$ & 3.7 & $\Rightarrow$ & $\Rightarrow$ & $\Rightarrow$ & 7.0 \\
\hline Position 6 & 5 & $\Rightarrow$ & 3.6 & $\Rightarrow$ & $\Rightarrow$ & $\Rightarrow$ & 7.4 \\
\hline
\end{tabular}


A-12

Table A.1 (continued)

\begin{tabular}{|c|c|c|c|c|c|c|}
\hline Parameter & CT -48 & CT-49A & CT-49B & CT-50A & CT-50B & CT-50C \\
\hline $\mathrm{Al}$ alloy material & 6061 & 6061 & $\Leftarrow$ & 6061 & $\Leftarrow$ & $\Leftrightarrow$ \\
\hline Test initiated & $6 / 95$ & $7 / 95$ & $7 / 95$ & $8 / 95$ & $8 / 95$ & $8 / 95$ \\
\hline $\mathrm{pH}$ & 4.8 & 5.07 & 4.88 & 5.05 & 5.20 & 5.39 \\
\hline $\mathrm{L}, \mu \mathrm{S} / \mathrm{m}$ & 900 & 450 & 575 & 370 & 290 & 200 \\
\hline $\mathrm{V}_{\mathrm{c}}, \mathrm{m} / \mathrm{s}$ & 11.2 & 7.5 & $\Leftarrow$ & 7.5 & $\Leftarrow$ & $\Leftarrow$ \\
\hline $\mathrm{T}_{c i,}{ }^{\circ} \mathrm{C}$ & 49 & 49 & $\Leftarrow$ & 49 & $\Leftarrow$ & $\Leftarrow$ \\
\hline $\mathrm{P}, \mathrm{kW}$ & 22.4 & 22.3 & $\Leftarrow$ & 22.3 & $\Leftarrow$ & $\Leftarrow$ \\
\hline$\phi_{\text {avg }}, M W / m^{2}$ & 6.2 & 6.2 & $\Leftarrow$ & 6.2 & $\Leftarrow$ & $\Leftarrow$ \\
\hline Duration, $\mathrm{h}$ & 92 & 130 & $\Rightarrow 225$ & 100 & $\Rightarrow 180$ & $\Rightarrow 240$ \\
\hline \multicolumn{7}{|l|}{ Local $\mathrm{T}_{c},{ }^{\circ} \mathrm{C}$} \\
\hline Position 2 & 53 & 56 & 55 & 56 & $\Leftarrow$ & $\Leftarrow$ \\
\hline Position 4 & 62 & 69 & 69 & 70 & $\Leftarrow$ & $\Leftarrow$ \\
\hline Position 6 & 71 & 82 & 82 & 83 & $\Leftarrow$ & $\Leftarrow$ \\
\hline \multicolumn{7}{|l|}{ Local $\mathrm{T}_{\mathrm{x} / \mathrm{c}},{ }^{\circ} \mathrm{C}$} \\
\hline Position 2 & 136 & 165 & 164 & 165 & $\Leftarrow$ & $\Leftarrow$ \\
\hline Position 4 & 143 & 175 & 174 & 175 & $\Leftarrow$ & $\Leftarrow$ \\
\hline Position 6 & 150 & 187 & 186 & 187 & $\Leftarrow$ & $\Leftarrow$ \\
\hline \multicolumn{7}{|l|}{ Local $\phi, M W / m^{2}$} \\
\hline Position 2 & 6.1 & 6.1 & 6.0 & 6.0 & $\Leftarrow$ & $\Leftarrow$ \\
\hline Position 4 & 6.2 & 6.2 & 6.1 & 6.2 & $\Leftarrow$ & $\Leftarrow$ \\
\hline Position 6 & 6.4 & 6.4 & 6.4 & 6.5 & $=$ & $\Leftarrow$ \\
\hline \multicolumn{7}{|c|}{ Rate con $(\mathrm{k}), \mu \mathrm{m}^{1.351} / \mathrm{h}$} \\
\hline Position 2 & 0.001 & 0.087 & 0.050 & 0.127 & 0.127 & 0.233 \\
\hline Position 4 & 0.002 & 0.122 & 0.066 & 0.163 & 0.163 & 0.283 \\
\hline Position 6 & 0.006 & 0.187 & 0.079 & 0.225 & 0.225 & 0.315 \\
\hline \multicolumn{7}{|l|}{ EOT film thk, $\mu \mathrm{m}$} \\
\hline Position 2 & $\mathrm{NA}$ & $\Rightarrow$ & 8.3 & $\Rightarrow$ & $\Rightarrow$ & 16.8 \\
\hline Position 4 & NA & $\Rightarrow$ & 11.8 & $\Rightarrow$ & $\Rightarrow$ & 20.2 \\
\hline Position 6 & NA & $\Rightarrow$ & 14.7 & $\Rightarrow$ & $\Rightarrow$ & 25.2 \\
\hline
\end{tabular}




\section{INTERNAL DISTRIBUTION}

1. J. R. DiStefano

2. D. K. Felde

3. H. W. Hayden

4-7. R. L. Johnson

8. J. F. King

9. R. E. Mesmer

10. D. A. Palmer

11. R. E. Pawel

12-16. S. J. Pawel

17. R. B. Rothrock
18. D. L. Selby

19. C. D. West

20. G. L. Yoder

21. ORNL Patent Office

22. Central Research Library, Document Reference Section

23. Y-12 Technical Library 24-25. Laboratory Records Dept.

26. Laboratory Records, RC

\section{EXTERNAL DISTRIBUTION}

27. E. Bauer, Institut Laue-Langevin, $156 \mathrm{X} 38042$, Grenoble Cedex, France

28. G. S. Bauer, Paul Scherrer Institut, CH-5232 Villigen PSI, Switzerland

29. K. Böning, Technical University of Munich, Reaktorstation, D-85747 Garching, Germany

30. B. Farnoux, DSM C. E. Saclay, ORME Des Merisiers, 91191 Gif-sur-Yvette Cedex, France

31. A. G. Lee, Atomic Energy of Canada, Ltd., Whiteshell Nuclear Research Establishment, Pinawa, Manitoba, ROE 1L0, Canada

32. J. C. McKibben, Research Reactor Facility, University of Missouri-Columbia, Research Park, Columbia, MO 65211

33. N. Ohnishi, Japan Atomic Energy Research Institute, Tokai-mura, Naka-gun, Ibaraki-ken, Japan 319-11

34. D. Rorer, Reactor Division, Building 120, Brookhaven National Laboratory, Upton, NY 11973

35. H.-J. Roegler, Siemens AG, KWU-NLS1, Postfach 1010 63, 63010 Offenbech, Germany

36. J. M. Rowe, National Institute of Standards and Technology, Washington, DC 20234

37. U.S. Department of Energy, ANS Project Office, Oak Ridge Operations Office, FEDC, MS-8218, P.O. Box 2009, Oak Ridge, TN 37831-8218

38-39. Office of Scientific and Technical Information, P.O. Box 63, Oak Ridge, TN 37831 
